\title{
Molecular mechanism of the chitinolytic monocopper peroxygenase reaction
}

Bastien Bissaro ${ }^{1}$, Bennett Streit ${ }^{2}$, Ingvild Isaksen ${ }^{1}$, Vincent G.H. Eijsink ${ }^{1}$, Gregg T. Beckham ${ }^{3}$ Jennifer DuBois $^{2 *}$ and Åsmund K. Røhr ${ }^{1 *}$

${ }^{1}$ Faculty of Chemistry, Biotechnology and Food Science, Norwegian University of Life Sciences (NMBU), P.O. Box 5003, N-1432 Aas, Norway

${ }^{2}$ Department of Chemistry and Biochemistry, Montana State University, Bozeman, MT 59717-3400, USA;

${ }^{3}$ National Bioenergy Center, National Renewable Energy Laboratory, Golden, CO 80401, USA

KEYWORDS: LPMO, CHITIN, CELLULOSE, BIOMASS, QM/MM, HYDROGEN PEROXIDE, PEROXYGENASE, MONOOXYGENASE, STOPPED-FLOW KINETICS

\section{GRAPHICAL ABSTRACT}

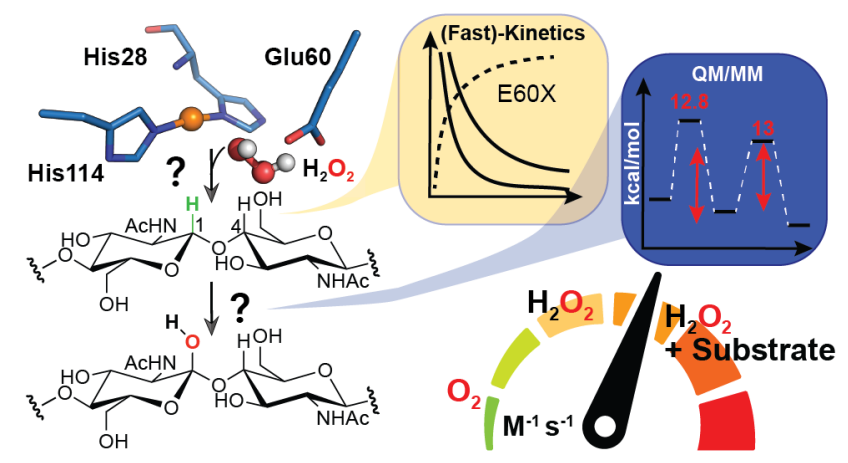




\begin{abstract}
Lytic polysaccharide monooxygenases (LPMOs) are a recently discovered class of monocopper enzymes, broadly distributed across the Tree of Life. We recently reported that LPMOs can use $\mathrm{H}_{2} \mathrm{O}_{2}$ as an oxidant, revealing a novel reaction pathway. Here, we aimed to elucidate the $\mathrm{H}_{2} \mathrm{O}_{2}$-mediated reaction mechanism with experimental and computational approaches. In silico studies suggest that a network of hydrogen bonds, involving both the enzyme and the substrate, brings $\mathrm{H}_{2} \mathrm{O}_{2}$ into a strained reactive conformation, and guides the derived hydroxyl radical towards formation of a copper-oxyl intermediate. The initial $\mathrm{H}_{2} \mathrm{O}_{2}$ homolytic cleavage and subsequent hydrogen atom abstraction from chitin by the copper-oxyl intermediate are suggested to be the main energy barriers. Under single turnover conditions, stopped-flow fluorimetry demonstrates that $\mathrm{LPMO}-\mathrm{Cu}(\mathrm{II})$ reduction to $\mathrm{Cu}(\mathrm{I})$ is a fast process compared to the re-oxidation reactions. We found that re-oxidation of $\mathrm{LPMO}-\mathrm{Cu}(\mathrm{I})$ is 2000 -fold faster with $\mathrm{H}_{2} \mathrm{O}_{2}$ than with $\mathrm{O}_{2}$, the latter being several orders of magnitude slower than rates reported for other monooxygenases. In agreement with the notion of ternary complex formation, when chitin is added, reoxidation by $\mathrm{H}_{2} \mathrm{O}_{2}$ is accelerated whereas that by $\mathrm{O}_{2}$ slows. Simulations indicated that Glu60, a highlyconserved residue, gates the access to the confined active site and constrains $\mathrm{H}_{2} \mathrm{O}_{2}$ during catalysis, and Glu60 mutations significantly decreased the enzyme performance. By providing molecular and kinetic insights into the peroxygenase activity of chitinolytic LPMOs, this study will aid the development of applications of enzymatic and synthetic copper catalysis and contribute to understanding pathogenesis, notably chitinolytic plant defenses against fungi and insects.
\end{abstract}




\section{INTRODUCTION}

The landscape of bioinorganic chemistry has recently been enriched by the discovery that oxidative monocopper enzymes named lytic polysaccharide monooxygenases (LPMOs) can use $\mathrm{H}_{2} \mathrm{O}_{2}$ as a natural co-substrate, ${ }^{1}$ whereas $\mathrm{O}_{2}$ has long been invoked in all other established paradigms of copper-based enzymatic catalysis. ${ }^{2}$. The uniqueness of LPMOs lies mainly in the fact that they have the ability to catalyze the oxidative cleavage of glycosidic chains found in complex, recalcitrant environments such as the crystalline lattices formed by chitin, ${ }^{3}$ cellulose, ${ }^{4-6}$ or co-polymeric structures. ${ }^{7,8}$ LPMO action has been shown to disrupt the surface of recalcitrant polysaccharides, ${ }^{9,10}$ in turn enhancing the depolymerization catalyzed by canonical glycoside hydrolases. ${ }^{3,11-13}$ LPMOs are today classified as auxiliary activities (AA) in the Carbohydrate active enzyme database, in families AA9 to 11 and AA13 to 15 . Given their biological abundance, notably in wood-decaying fungi, ${ }^{14}$ it is not surprising that LPMOs have rapidly become key elements of commercial enzymatic cocktails ${ }^{15-17}$ used in the biorefinery industry. ${ }^{18}$ Recent developments indicate that chitin-active LPMOs may play roles beyond biomass decomposition, such as acting as virulence factors in bacterial infections. ${ }^{19-21}$ On a similar note, a 2016 study showed that a "chitin-binding" protein (Tma12) is expressed by ferns as an insecticidal agent against whitefly. ${ }^{22}$ Importantly, although not recognized then as such, Tma12 resembles typical LPMOs: homology modeling shows a typical slightly distorted Fibronectin-like/Immunoglobulin-like $\beta$-sandwich core displaying the two surface-exposed, conserved histidines and phylogenetic analysis shows clustering with AA10 family members (Figure S3).

Despite substantial progress within the last decade, the mode of action of these monocopper enzymes is not yet fully mechanistically characterized. ${ }^{16,23-25}$ When acting on a carbohydrate substrate $(\mathrm{R}-\mathrm{H})$, and in the presence of excess reductant, a single oxygen atom derived from $\mathrm{O}_{2}$ is introduced into the final product, ${ }^{3,26}$ explaining why LPMOs have been widely recognized as monooxygenases. ${ }^{26}$ However, the monooxygenase reaction $\left(\mathrm{R}-\mathrm{H}+\mathrm{O}_{2}+2 \mathrm{e}^{-}+2 \mathrm{H}^{+} \rightarrow \mathrm{R}-\mathrm{OH}+\mathrm{H}_{2} \mathrm{O}\right)$ requires a second electron (the first one being stored as $\mathrm{Cu}(\mathrm{I})$ ) and protons during catalysis. These catalytic events remained highly puzzling considering (i) the monocopper, organic cofactor-free nature of LPMOs and (ii) that access of reductants to the active site is limited when bound to a polysaccharide substrate. ${ }^{27}$ Facing this question, Bissaro et al. demonstrated that LPMOs are capable of efficiently using $\mathrm{H}_{2} \mathrm{O}_{2}$ as a source of oxygen atoms in the hydroxylation reaction, thus making LPMOs a new kind of copperdependent peroxygenase ( $\mathrm{R}-\mathrm{H}+\mathrm{H}_{2} \mathrm{O}_{2} \rightarrow \mathrm{R}-\mathrm{OH}+\mathrm{H}_{2} \mathrm{O}$; Figure 1). ${ }^{1,28}$ These findings suggest a straightforward answer to the "second electron conundrum", since $\mathrm{H}_{2} \mathrm{O}_{2}$ brings the oxygen, electron, and proton equivalents necessary for a complete catalytic cycle. Such chemistry is new in the field of copper-enzymes and sparks interest in unraveling a new, $\mathrm{H}_{2} \mathrm{O}_{2}$-dependent mechanism. Although previous studies attempting to decipher the molecular details of the LPMO mechanism were carried out in a monooxygenase context, some conclusions drawn at that time are likely still valid but deserve to be re-investigated. Notably, a quantum mechanical (QM) study ${ }^{29}$ followed by several other computational studies, ${ }^{30,31}$ suggested that the most likely species responsible for hydrogen atom abstraction (HAA) is a copper(II)-oxyl $\left([\mathrm{CuO}]^{+}\right.$) species. A similar downstream intermediate has been proposed for the $\mathrm{H}_{2} \mathrm{O}_{2}$ reaction mechanism, ${ }^{1}$ where $[\mathrm{CuO}]^{+}$is obtained after reaction of $\mathrm{H}_{2} \mathrm{O}_{2}$ with the LPMO-Cu(I) state, concomitant with $\mathrm{H}_{2} \mathrm{O}$ release.

Wang et al. ${ }^{32}$ recently published a computational study on an C4-oxidizing AA9 in complex with a water soluble cellotriose molecule ${ }^{33}$ that is line with the proposed peroxygenase mechanism. ${ }^{1}$ However, no supporting biochemical data on $\mathrm{H}_{2} \mathrm{O}_{2}$ reactivity have been reported for that AA9. Subsequent to the discovery of the role of $\mathrm{H}_{2} \mathrm{O}_{2}$ in LPMO catalysis, a study by Kuusk et al. determined the steady-state kinetic parameters of $\mathrm{H}_{2} \mathrm{O}_{2}$-driven chitin oxidation by the $\mathrm{C}$ 1-oxidizing LPMO from the soil bacterium Serratia marscecens (SmAA10A, also known as CBP21). ${ }^{34}$ This study revealed a 
catalytic constant $\left(k_{\text {cat }}\right)$ of $6.7 \mathrm{~s}^{-1}$ and an apparent $K_{\mathrm{M}}$ for $\mathrm{H}_{2} \mathrm{O}_{2}$ in the low micromolar range (ca. $\left.3 \mu \mathrm{M}\right)$ resulting in a $k_{\mathrm{cat}} / K_{\mathrm{M}} \sim 10^{6} \mathrm{M}^{-1} \mathrm{~s}^{-1}$. These constants are consistent with values reported for wellcharacterized heme-dependent peroxygenases. ${ }^{35}$

Building on biochemical and steady-state kinetics evidence gathered for SmAA10A, ${ }^{1,34}$ and also on experimentally-supported molecular models of SmAA10A on crystalline chitin complexes, ${ }^{27}$ we aimed to decipher the molecular details of the newly proposed $\mathrm{H}_{2} \mathrm{O}_{2}$ reaction mechanism. Employing several computational methods, we calculated the energy barriers associated with hypothesized reaction coordinates and $\mathrm{H}_{2} \mathrm{O}_{2}$ diffusion pathways to the active site. As experimental support, we used pre-steady state kinetic methods to examine $S m \mathrm{AA} 10 \mathrm{~A}$ reduction and single turnover reactions of $S m \mathrm{AA} 10 \mathrm{~A}$, isolated in the $\mathrm{Cu}(\mathrm{I})$ form, with both $\mathrm{H}_{2} \mathrm{O}_{2}$ and $\mathrm{O}_{2}$. QM/MM calculations suggested a key role in catalysis for Glu60, a highly conserved second-shell residue, which was subsequently interrogated experimentally by site directed mutagenesis. Collectively, these results provide a strong mechanistic and thermochemical foundation for describing chitinolytic LPMOs as unusual biological peroxygenases functioning through a $[\mathrm{CuO}]^{+}$intermediate.

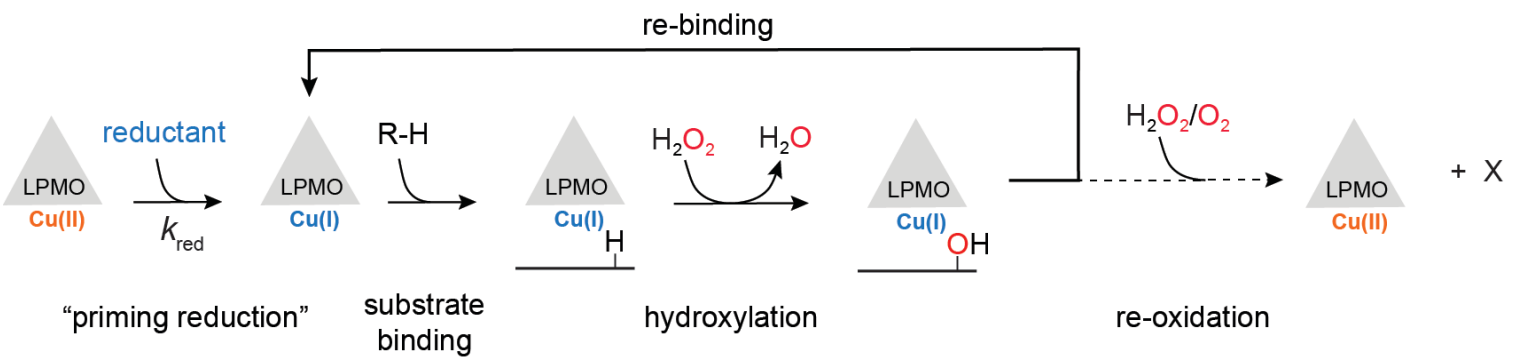

Figure 1. Simplified reaction scheme of $\operatorname{SmAA10A-catalyzed~peroxygenation~of~chitin.~Reduction~of~the~}$ ground state LPMO-Cu(II) to LPMO-Cu(I), which binds with greater affinity to substrate, ${ }^{36,37}$ is thought to precede substrate binding leading to a confined active site ${ }^{27}$ ready to react with $\mathrm{H}_{2} \mathrm{O}_{2}$, resulting in hydroxylation of the substrate and release of a water molecule. ${ }^{1}$ The hydroxylated product (either at the $\mathrm{C} 1$ or $\mathrm{C} 4$ carbon) is unstable and undergoes an elimination reaction inducing glycosidic bond cleavage. ${ }^{26,32}$ At the end of the catalytic cycle, the $\mathrm{Cu}(\mathrm{I})$ state is conserved, and the enzyme could potentially enter a new catalytic cycle or be oxidatively inactivates via non-productive reactions with oxidants. $\mathrm{X}$ denotes the reaction products (e.g. hydroxyl radicals, superoxide) originating from such de-activation reactions. 


\section{EXPERIMENTAL AND COMPUTATIONAL DETAILS SECTION}

A complete description of the experimental details is available in the Supporting information document, including details on materials, site-directed mutagenesis, production and purification of recombinant LPMOs, LPMO activity and binding assays, (stopped-flow) fluorimetry experiments and computational studies.

\section{RESULTS}

$\mathrm{H}_{2} \mathrm{O}_{2}$ is the co-substrate sustaining $\mathrm{SmAA10A}$ catalysis under steady-state turnover conditions. $\mathrm{H}_{2} \mathrm{O}_{2}$ has previously been shown to serve as an efficient co-substrate of SmAA10A-catalyzed oxidation of chitin. ${ }^{34}$ However, the question remains whether $S m$ AA10A catalysis also relies on $\mathrm{H}_{2} \mathrm{O}_{2}$ in conditions where $\mathrm{H}_{2} \mathrm{O}_{2}$ is not added, i.e. just in presence of ambient $\mathrm{O}_{2}$ concentrations and excess reductant. The latter conditions are standard practice in the LPMOs field. We argued previously that they promote the in situ formation of $\mathrm{H}_{2} \mathrm{O}_{2}$, and therefore that most reported LPMO rates reflected a peroxygenase rather than a putative monooxygenase activity. Here, we first carried out a competition experiment in presence of a peroxidase (Figure 2A). This experiment shows that, in presence of ambient $\mathrm{O}_{2}$ (no added $\mathrm{H}_{2} \mathrm{O}_{2}$ ) and $1 \mathrm{mM}$ reductant (ascorbic acid, AscA), $1 \mu \mathrm{M}$ SmAA10A can be almost totally inhibited by the $\mathrm{H}_{2} \mathrm{O}_{2}$ scavenging activity of $\mathrm{HRP}$, suggesting that $\mathrm{H}_{2} \mathrm{O}_{2}$ is produced in situ and is the main (if not only) oxidant used by SmAA10A. In agreement with the proposal of the formation of a ternary complex founded on the basis of steady-state kinetics studies, ${ }^{34}$ we show, after determining suitable reaction conditions (i.e. $50 \mathrm{nM}$ LPMO and $50 \mu \mathrm{M}$ EDTA to diminish non-enzymatic background reactions; see Figure S6), that fast and efficient $\mathrm{H}_{2} \mathrm{O}_{2}$ consumption only occurs in the presence of both $S m$ AA10A and $\beta$-chitin (Figure 2B).
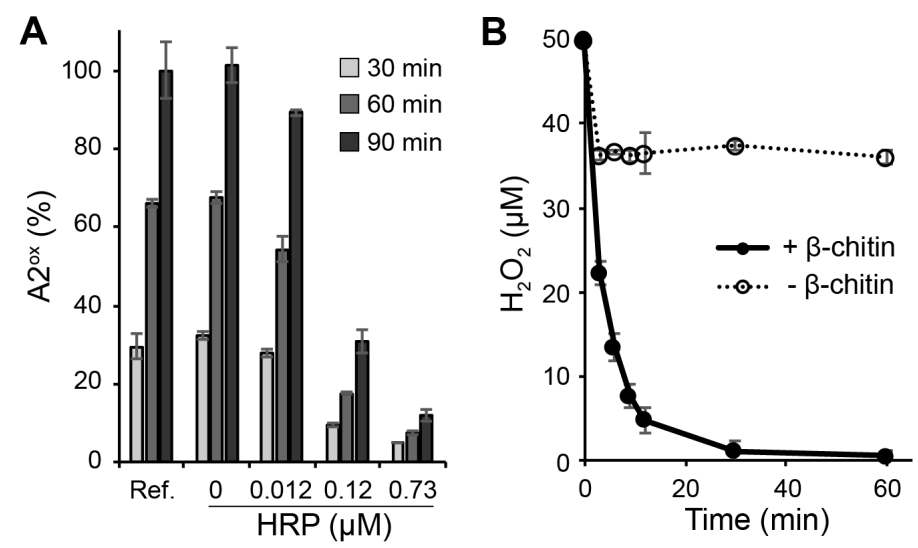

Figure 2. Assessing the underlying role of $\mathrm{H}_{2} \mathrm{O}_{2}$ in $\mathrm{SmAA10A-catalyzed} \mathrm{oxidation} \mathrm{of} \mathrm{chitin.} \mathrm{(A)} \mathrm{The} \mathrm{graph}$ shows the time-course release of soluble oxidized products (chitobionic acid; A2 ${ }^{\text {ox }}$ ) from $\beta$-chitin $\left(10 \mathrm{mg} \cdot \mathrm{mL}^{-1}\right)$ by $\operatorname{SmAA10A}(1 \mu \mathrm{M})$ in presence of AscA $(1 \mathrm{mM})$ and $\mathrm{O}_{2}$ (ca. $200 \mu \mathrm{M}$ at atmospheric pressure) with different amounts of horseradish peroxidase (HRP) and AmplexRed (200 $\mu \mathrm{M}$, a co-substrate of HRP). Quantities are expressed as a percentage of the amount of $A 2^{\text {ox }}$ detected in the reference reaction ("Ref."; i.e without HRP and AmplexRed) after $90 \mathrm{~min}$ reaction. (B) Time-course consumption of $\mathrm{H}_{2} \mathrm{O}_{2}\left(50 \mu \mathrm{M}\right.$ at $\left.\mathrm{t}_{0}\right)$ by $\operatorname{SmAA} 10 \mathrm{~A}(50 \mathrm{nM})$ in a reaction containing AscA $(20 \mu \mathrm{M})$ and EDTA ( $50 \mu \mathrm{M}$; see Figure S6 for details) in presence and absence of $\beta$ chitin $\left(10 \mathrm{mg} \cdot \mathrm{mL}^{-1}\right)$. Note that the fast drop observed for instance in the "no chitin" experiment is due to some experimental limitations (Figure S7). All reactions were carried out in sodium phosphate buffer (50 $\mathrm{mM}, \mathrm{pH} 7.0)$ at $40{ }^{\circ} \mathrm{C}$ in a thermomixer $(1,000 \mathrm{rpm})$. Error bars show \pm s.d. $(\mathrm{n}=3$, independent experiments $)$. 
$Q M / M M$ study of the chitinolytic peroxygenase reaction. Intriguingly, neither strict C1-oxidizing LPMOs, nor crystalline polysaccharide substrates, have been the subject of QM/MM-assisted investigations of the LPMO mechanism. ${ }^{29,31,32,38-40}$ Also, in the few available reports, ${ }^{32,40}$ the initial steps of $\mathrm{H}_{2} \mathrm{O}_{2}$ access, positioning, and one electron reduction by $\mathrm{Cu}(\mathrm{I})$ at the enzyme active site have not been described and have not been agreed upon (vide infra). Starting from a previously published, biochemically and spectroscopically supported model of SmAA10A in complex with crystalline $\beta$-chitin (Figures 3A and S4), ${ }^{27}$ we performed $\mathrm{QM} / \mathrm{MD}$ and $\mathrm{QM} / \mathrm{MM}$ calculations to unravel the molecular details underlying the peroxygenase reaction $\left(\mathrm{R}-\mathrm{H}+\mathrm{H}_{2} \mathrm{O}_{2} \rightarrow \mathrm{R}-\mathrm{OH}+\mathrm{H}_{2} \mathrm{O}\right)$ catalyzed by $S m$ AA10A$\mathrm{Cu}(\mathrm{I})$.

QM/MM/MD simulations (Figure S5, Movie S1), followed by NEB minimum energy path calculations resulted in starting models for calculating the energies of the different states (1-9) of the SmAA10A-catalyzed reaction (Figure 3D). A global observation is that the overall reaction is thermodynamically favorable, with a relative energy difference of $-65.9 \mathrm{kcal} \mathrm{mol}^{-1}$ between the initial and final states. State 1 represents the $S m A A 10 A-C u(I)$ bound to $\beta$-chitin substrate with a $\mathrm{H}_{2} \mathrm{O}_{2}$ molecule confined in the reaction cavity and no water molecules coordinated to the copper ion. Hydrogen bonds from the Glu60 side chain and a substrate amide hydrogen align the $\mathrm{H}_{2} \mathrm{O}_{2}$ molecule towards the $\mathrm{Cu}(\mathrm{I})$ ion at a distance of $2.98 \AA$ (Figure 3B). The $\mathrm{H}_{2} \mathrm{O}_{2} \mathrm{O}$-O bond length of $\mathbf{1}$ is $1.44 \AA$, which is equal to the value obtained by geometry optimization of $\mathrm{H}_{2} \mathrm{O}_{2}$ in vacuum (1.44 $\AA$ ). Interestingly, the dihedral bond angle of $\mathrm{H}_{2} \mathrm{O}_{2}$ in $\mathbf{1}$ is $53^{\circ}$, far from the equilibrium angle $\left(113.6^{\circ}\right.$ in gaseous state, ${ }^{41} 90.2^{\circ}$ in solid state ${ }^{42}$ ), indicating that the protein and substrate introduce a strained conformation $\left(+4.1 \mathrm{kcal} \mathrm{mol}^{-1}\right)$ of the peroxide moiety. The $S m A A 10$ A catalytic cycle is triggered by electron transfer from $\mathrm{Cu}(\mathrm{I})$ to $\mathrm{H}_{2} \mathrm{O}_{2}$, and the transition state of this step is represented by 2 (Figure 3C). The $\mathrm{H}_{2} \mathrm{O}_{2}$ bond is now elongated $(1.76 \AA)$, the dihedral bond angle has relaxed to $94^{\circ}$, and the proximal peroxide O-atom is only $2.1 \AA$ away from the copper ion. The energy barrier of this step is estimated to be $12.8 \mathrm{kcal} \mathrm{mol}^{-1}$ and $8.6 \mathrm{kcal}$ $\mathrm{mol}^{-1}$ by the functionals B3LYP and TPSSh, respectively. State $\mathbf{2}$ is best described as an open-shell singlet, but reaching that conclusion required detailed analysis of the electronic structure (see Supplementary Results). We plotted the quasi-restricted orbitals that best describe the transition of state $\mathbf{1}$ to $\mathbf{2}$ in Figure 3C. The highest occupied molecular orbital (HOMO) of state $\mathbf{1}$ has mainly $\mathrm{Cu}-$ $\mathrm{d}_{\mathrm{x} 2-\mathrm{y} 2}$ and ligand $\pi$ character (Figure 3C, "1-HOMO"), and the largest lobe points directly towards the $\mathrm{H}_{2} \mathrm{O}_{2}$ molecule. Reaching the transition state geometry (state 2), the HOMO orbital is also slightly delocalized to include the $\mathrm{H}_{2} \mathrm{O}_{2}$ molecule (Figure 3C, "2-HOMO"). According to frontier molecular orbital theory, the lowest unoccupied molecular orbital (LUMO) indicates where the $\mathrm{Cu}(\mathrm{I})$ electron will go. Here, the state 2 LUMO displays a decreased density at the copper d-orbital, while a $\sigma^{*}$ anti-bonding orbital appears between the $\mathrm{H}_{2} \mathrm{O}_{2} \mathrm{O}$-atoms (Figure 3C, "2-LUMO"), rationalizing the homolytic cleavage of the O-O bond. The first local minimum in the reaction path is state 3 (Figure 3D and S8), where the calculations suggest a $\mathrm{Cu}$-bound hydroxide with an adjacent hydroxyl radical. This state also collapses to an open shell singlet solution due to strong antiferromagnetic coupling between the $\mathrm{Cu}$ (II) and hydroxyl radical (See Supplementary Results for more details). Hydrogen bonds from both the substrate and the protein appear to confine and orient the reactive hydroxyl radical in the reaction cavity, yielding a "precision-guided $\mathrm{HO}$ " poised for hydrogen atom abstraction from the $\mathrm{Cu}$-bound hydroxide with a barrier of $6.5 \mathrm{kcal} \mathrm{mol}^{-1}$ (B3LYP; state 4, Figure S8). At this point, the total spin of the system has changed from a singlet to a triplet state displaying spin crossover behavior. The resulting state $\mathbf{5}$ (Figure 3D and S8) is best described as a triplet copper-oxyl $[\mathrm{CuO}]^{+}$species, where the oxyl-O atom, now only $2.08 \AA$ away from the substrate $\mathrm{H}$-atom that is to be abstracted, is hydrogen bonded to the water molecule formed in the previous reaction step. In this highly reactive state, a Löwdin spin population analysis reveals $\mathrm{Cu}$ and oxyl spins of 0.61 and 1.1, respectively (see Table S2 for all values along the reaction path). 

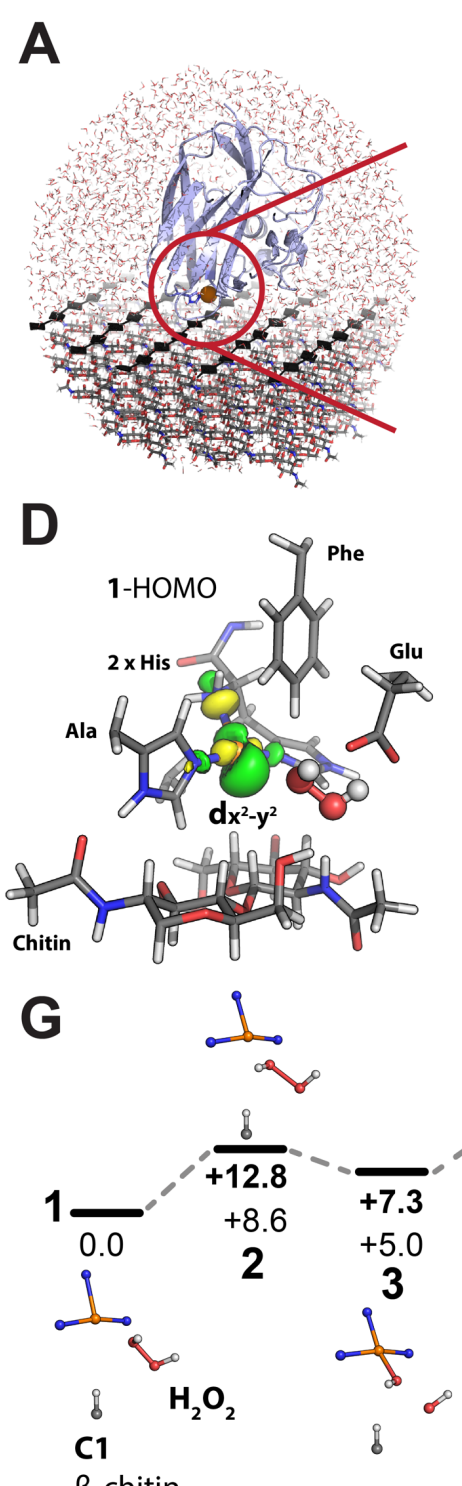

$\beta$-chitin
B

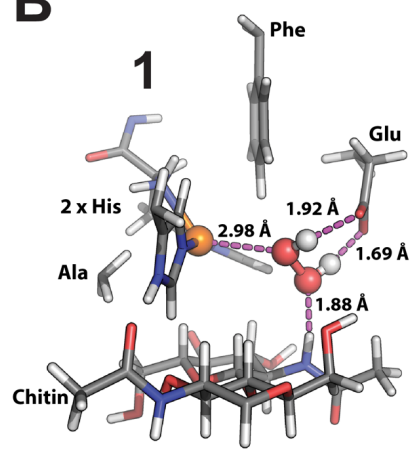

$\mathrm{E}$

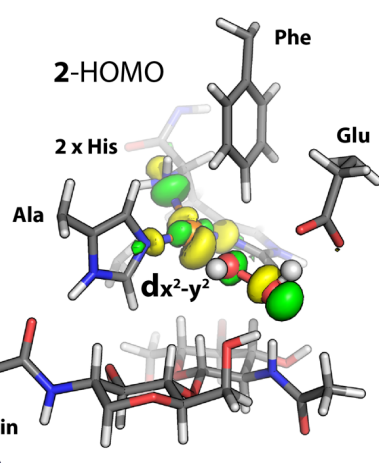

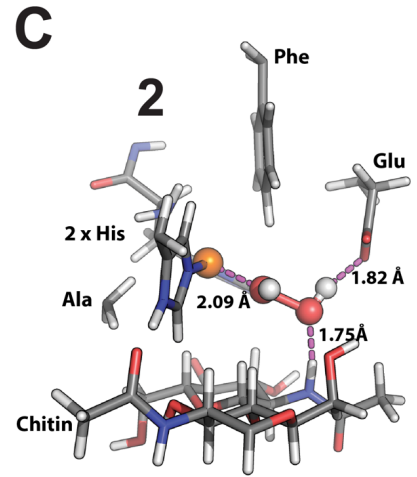

$\mathbf{F}$
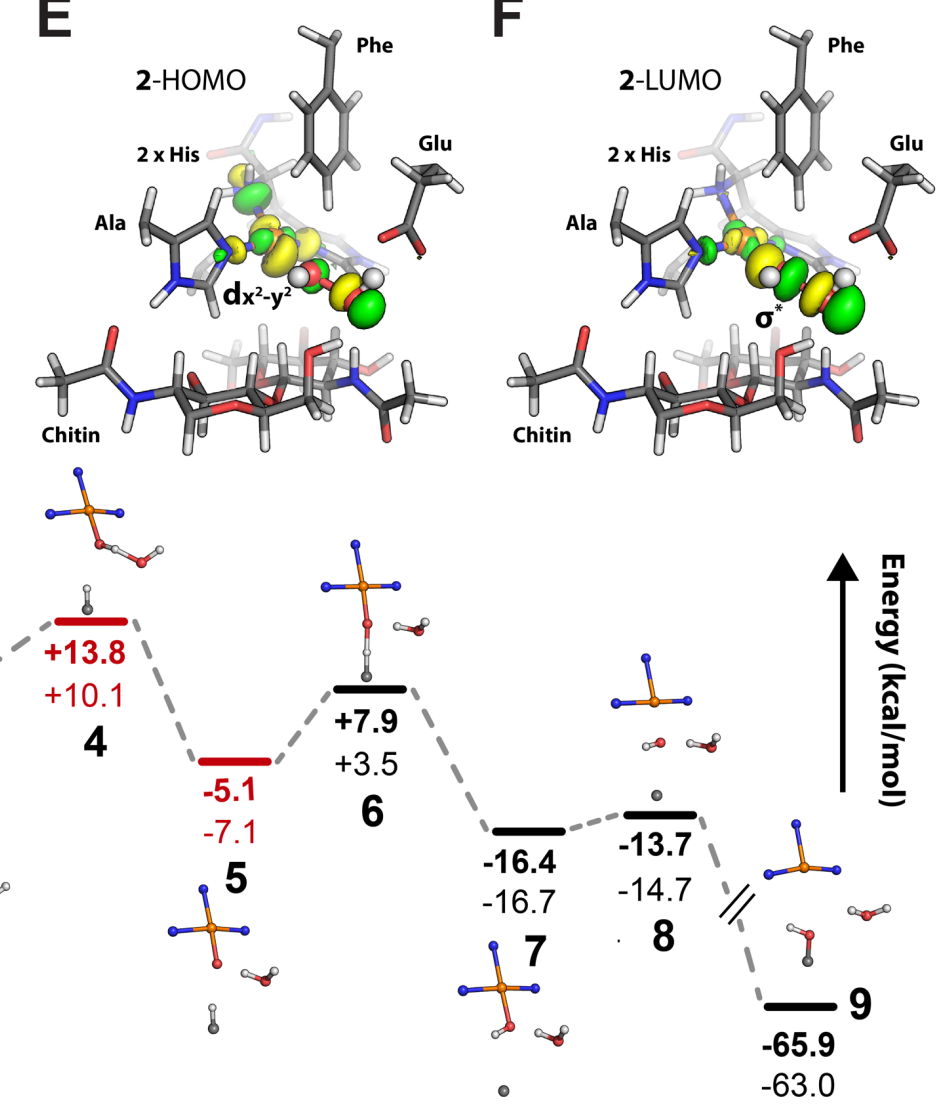

Figure 3. QM/MM study of the peroxygenase mechanism of $\operatorname{SmAA10A}$ on crystalline $\beta$-chitin. (A) The QM/MM model containing $\sim 24,000$ atoms derived from experimentally-supported models of SmAA10A in complex with chitin. ${ }^{27}$ See Figure S5 for a definition of the QM region. (B) In the initial state of the reaction (1), the $\mathrm{H}_{2} \mathrm{O}_{2}$ molecule is aligned toward the $\mathrm{Cu}(\mathrm{I})$ ion in a strained conformation by both substrate and amino acid side chain hydrogen bonds. The first transition state (2) displays an elongated $\mathrm{H}_{2} \mathrm{O}_{2} \mathrm{O}-\mathrm{O}$ bond and the reactive hydroxyl radical to be formed is stabilized by $\mathrm{H}$-bonds from Glu60 and a substrate amide $\mathrm{H}$-atom. (C) The electron transfer from $\mathrm{Cu}(\mathrm{I})$ to $\mathrm{H}_{2} \mathrm{O}_{2}$ can be visualized by plotting the quasi-restricted orbitals of $\mathbf{1}$ and $\mathbf{2}$. Before reaction with $\mathrm{H}_{2} \mathrm{O}_{2}$, the state $1 \mathrm{HOMO}$ exhibits delocalized $\mathrm{d}_{\mathrm{x} 2-\mathrm{y} 2}$ character, indicating a $\mathrm{Cu}(\mathrm{I})$ state ready to react with $\mathrm{H}_{2} \mathrm{O}_{2}$. The state 2 ("2-HOMO" to "2-LUMO" transition) indicates that the $\mathrm{Cu}(\mathrm{I})$ electron moves from the delocalized $\mathrm{d}_{\mathrm{x} 2-y_{2}}$ like orbital to a $\sigma^{*}$ anti-bonding orbital localized between the $\mathrm{H}_{2} \mathrm{O}_{2} \mathrm{O}$-atoms, promoting bond cleavage. (D) Complete reaction path where states 1-9 indicate energy minima and transition states (relative energies in kcal mol ${ }^{-1}$ ) (see Figure S8 for snapshots of each states). Between states $\mathbf{3}$ and $\mathbf{6}$, spin crossovers occur, and the triplet states are shown in red and the open shell singlet states are indicated in black. Numbers in bold are obtained by the B3LYP functional while the numbers immediately below were obtained by TPSSh. All protein residues and chitin (only a dimer is shown in panels $\mathrm{B}$ and $\mathrm{C}$ ) are displayed as grey sticks. $\mathrm{H}_{2} \mathrm{O}_{2}$ is shown as white and red sticks-and-balls. For the sake of clarity, the MM-region is not shown. HOMO, highest occupied molecular orbital; LUMO, lowest unoccupied molecular orbital. 
The energy barrier of the substrate H-abstraction step (state 6, Figures 3D and S8) depends on the functional utilized in the calculations. The B3LYP and TPSSh functionals yield values of 13.0 and 10.6 $\mathrm{kcal} \mathrm{mol}^{-1}$, respectively. At this point of the reaction, the system has changed back to the singlet energy surface indicating that the spin crossover transitions take place between state $\mathbf{3}$ and $\mathbf{6}$ in the reaction path. The hydroxide moiety formed by the $\mathrm{H}$-abstraction step partly recombines with the copper ion (Cu-O distance of $1.91 \AA$ ) in a local energy minimum (state 7, Figures 3D and S8). Finally, the Cuinteracting hydroxide passes through the low barrier $\left(+2.6 \mathrm{kcal} \mathrm{mol}^{-1}\right.$ for B3LYP) rebound-intermediate (state 8, Figure 3D and S8), and recombines with the substrate radical to form the final hydroxylated product (state 9, Figure 3D and S8). Note that the $\mathrm{Cu}(\mathrm{I})$ form of the enzyme has been regenerated at the end of the reaction cycle. Importantly, it appears that along the reaction path, hydrogen bonds from the enzyme Glu60 side chain and a strategically positioned substrate amide hydrogen control the positioning of several $\mathrm{H}_{2} \mathrm{O}_{2}$-derived reactive oxygen species (Figure S8), facilitating the LPMO reaction.

We also investigated an alternative mechanism, inspired by a previous study, ${ }^{29}$ where a $\mathrm{Cu}(\mathrm{I})$ activated $\mathrm{O}_{2}$ performs the substrate $\mathrm{H}$-abstraction at the triplet energy surface (Figure S9). The main conclusions are that substrate binding alters the orientation of the copper-bound superoxide, and that $\mathrm{H}$ abstraction by a copper superoxide intermediate is thermodynamically plausible but kinetically very unlikely (energy barrier of $35 \mathrm{kcal} \mathrm{mol}^{-1}$ ) (see Supplementary Results).

The reductive priming reaction is fast and monophasic. To gain insights into the priming reduction, i.e. the ability of an LPMO to catalyze the peroxygenase reaction once primed by substoichiometric amounts of reductant, ${ }^{1,37}$ we investigated how fast such reductive reaction occurs and which amount of reductant is required to achieve complete LPMO reduction. We have previously shown $^{43}$ that the fluorescence signal of an LPMO can be used as a reporter of the redox state of the LPMO (Figure S10), the $\mathrm{Cu}(\mathrm{II})$ and $\mathrm{Cu}$ (I) forms having respectively low and high fluorescence responses, both linear within the concentration range studied (Figure S11). Following rapid stoppedflow mixing of SmAA10A-Cu(II) with 1 eq. AscA (5 $\mu \mathrm{M}$ each) under anaerobic conditions, a monophasic increase in fluorescence was observed. The experiment was subsequently repeated with AscA present in pseudo-first order excess of the $\operatorname{SmAA10A-Cu(II)~(~} \geq 10$ eq). The total fluorescence change remained the same, suggesting that reduction was complete with as little as 1 eq. of AscA. The reduction reaction remained monophasic but increased in rate with increasing concentrations of AscA (Figure 4A). Each fluorescence versus time curve could be fit with a single exponential function, indicative of a pseudo-first order rate reaction with respect to AscA. The pseudo-first order rate constant $\left(k_{\mathrm{obs}}\right)$ varied linearly with [AscA], yielding a second order rate constant $k_{\mathrm{AscA}}=4.2 \times 10^{5} \mathrm{M}^{-1} \mathrm{~s}^{-1}$ (Figure 4B).

We showed (vide infra) that hexa- $N$-acetyl-chitohexaose $\left(\mathrm{NAG}_{6}\right)$ is a suitable substrate for single turnover experiments. Here, we show that in the presence of $1 \mathrm{mM} \mathrm{NAG}_{6}$ a second order rate constant of $5.4 \times 10^{5} \mathrm{M}^{-1} \mathrm{~s}^{-1}$ is obtained for the reduction of $\operatorname{SmAA10A-Cu}(\mathrm{II})$ by AscA (Figure S12). This value is 1.26 -fold higher than that obtained in absence of $\mathrm{NAG}_{6}$, suggesting that the presence of a bound substrate does not strongly modulate the rate of reaction of the $S m \mathrm{AA} 10 \mathrm{~A}-\mathrm{Cu}$ (II) by AscA.

The reaction between $\mathrm{Sm} A A 10 A-C u(I)$ and $\mathrm{O}_{2}$ is exceedingly slow. To further understand the hypothetical competition between environmentally available $\mathrm{H}_{2} \mathrm{O}_{2}$ and ambient $\mathrm{O}_{2}$, we first monitored the single turnover reaction of $2 \mu \mathrm{M} S m \mathrm{AA} 10 \mathrm{~A}-\mathrm{Cu}(\mathrm{I})$ (produced anaerobically by reduction of the oxidized enzyme with ascorbate, followed by removal of excess reductant) and $\mathrm{O}_{2}$ over time (Figure 
5A). The change in the fluorescence spectrum following mixing with 1 eq. $\mathrm{O}_{2}$ was not possible to discriminate from the background noise (not shown). Using pseudo-first order concentrations of $\mathrm{O}_{2}$ $\left(\left[\mathrm{O}_{2}\right]\right.$ at least a 10 -fold excess relative to $\left.[\operatorname{SmAA} 10 \mathrm{~A}-\mathrm{Cu}(\mathrm{I})]\right)$, the reaction led to re-oxidation of the $\mathrm{Cu}(\mathrm{I})$ to $\mathrm{Cu}(\mathrm{II})$ over a period of minutes, to an extent that was dependent on $\left[\mathrm{O}_{2}\right]$. When fitting the kinetic data, a number of models were explored (Figures S13 and S14).
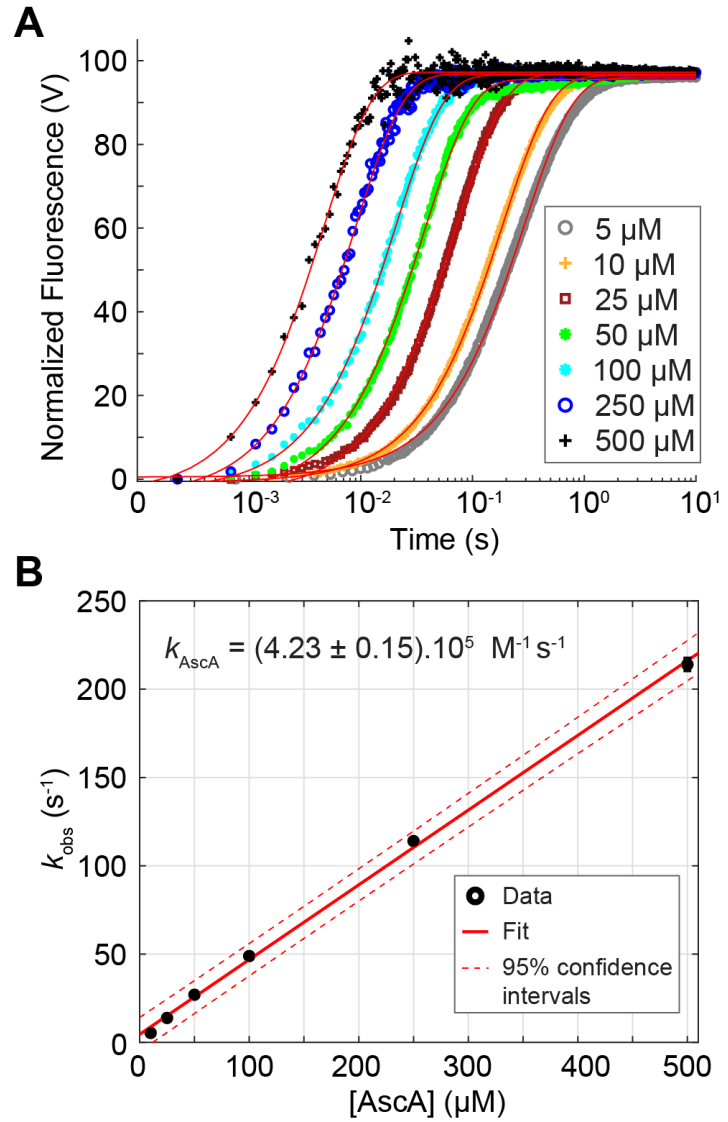

Figure 4. Kinetics and ascorbate concentration dependence of the reduction of $\operatorname{SmAA10A-Cu(II)~to~} \mathrm{Cu}(\mathrm{I})$. (A) $\operatorname{SmAA10A}-\mathrm{Cu}$ (II) (final concentration, $5 \mu \mathrm{M}$ ) was anaerobically mixed with varying concentrations of AscA and the changes in fluorescence associated with reduction of the $\mathrm{Cu}(\mathrm{II})$ monitored as a function of time. The reactions were carried out in potassium phosphate buffer $(50 \mathrm{mM}, \mathrm{pH} 7.1)$ at $25^{\circ} \mathrm{C}$. The final concentrations of AscA are indicated in the figure. Data were fit with single exponential functions (red lines) to give observed rate constants $\left(k_{\mathrm{obs}}\right)$ at each substrate concentration. Each experiment was performed in triplicate. For the sake of clarity, only the trace of one replicate is shown for each condition. (B) Plot of pseudo-first order $k_{\text {obs }}$ as a function of AscA concentration. Error bars show \pm s.d. $(n=3$, independent experiments).

Although we have based our analysis on a simple model, a single exponential function combined with a linear function (Figure S13\&14B), the residuals of the fits indicate that the re-oxidation of SmAA10A$\mathrm{Cu}(\mathrm{I})$ by $\mathrm{O}_{2}$ is a complex reaction. Indeed, a complex reaction model where $\mathrm{O}_{2}$ binds and is reduced by a binuclear copper cluster formed by a $\operatorname{SmAA} 10 \mathrm{~A}-\mathrm{Cu}(\mathrm{I})$ dimer results in a perfect fit (Figure S15, scheme S1). In such an arrangement, the $\operatorname{SmAA10A-Cu(I)~dimer~binuclear~active~site~would~resemble~}$ well-studied type 3 copper enzymes such as tyrosinases and hemocyanins. ${ }^{2}$ This dimer-hypothesis is currently being explored in a separate study. Nonetheless, applying the single exponential model as best simple approximation shows that the $k_{\mathrm{obs}}$ varied linearly with $\left[\mathrm{O}_{2}\right]$, yielding a second order rate constant $k_{02}=3.3 \mathrm{M}^{-1} \mathrm{~s}^{-1}$ (Figure 5B). 
A
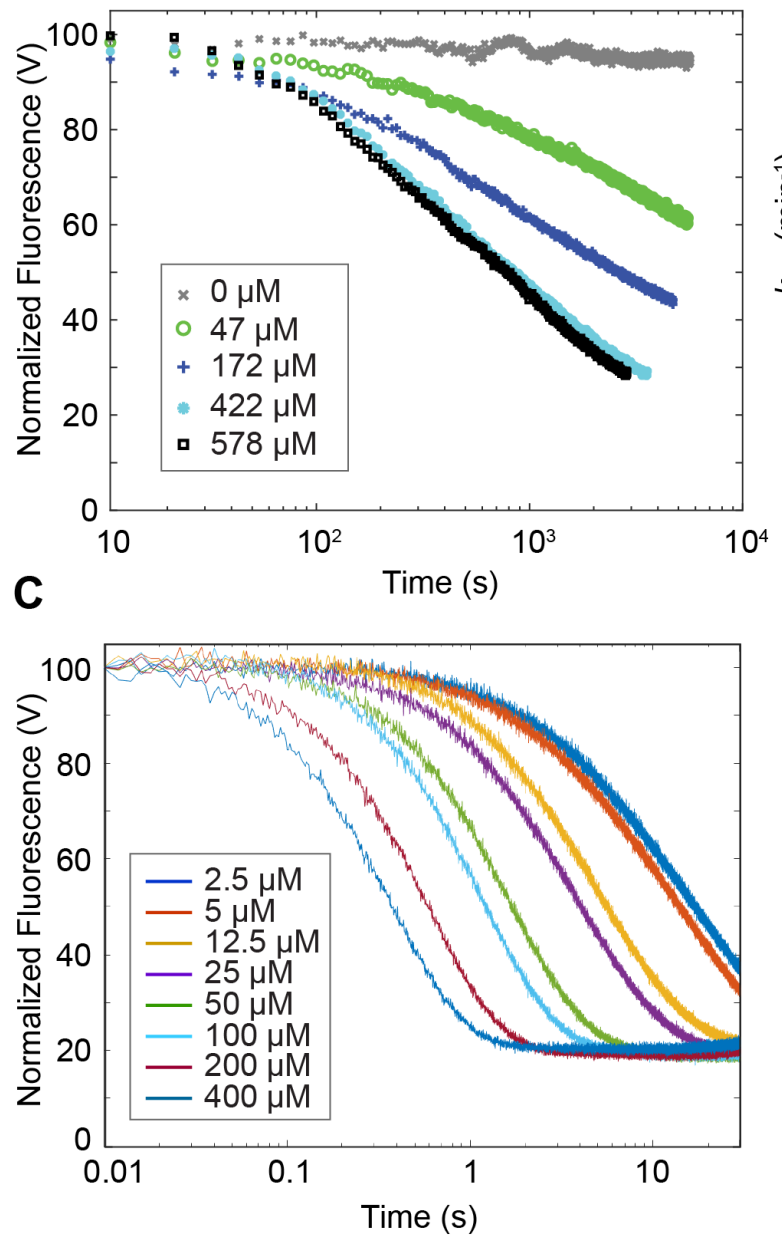

B
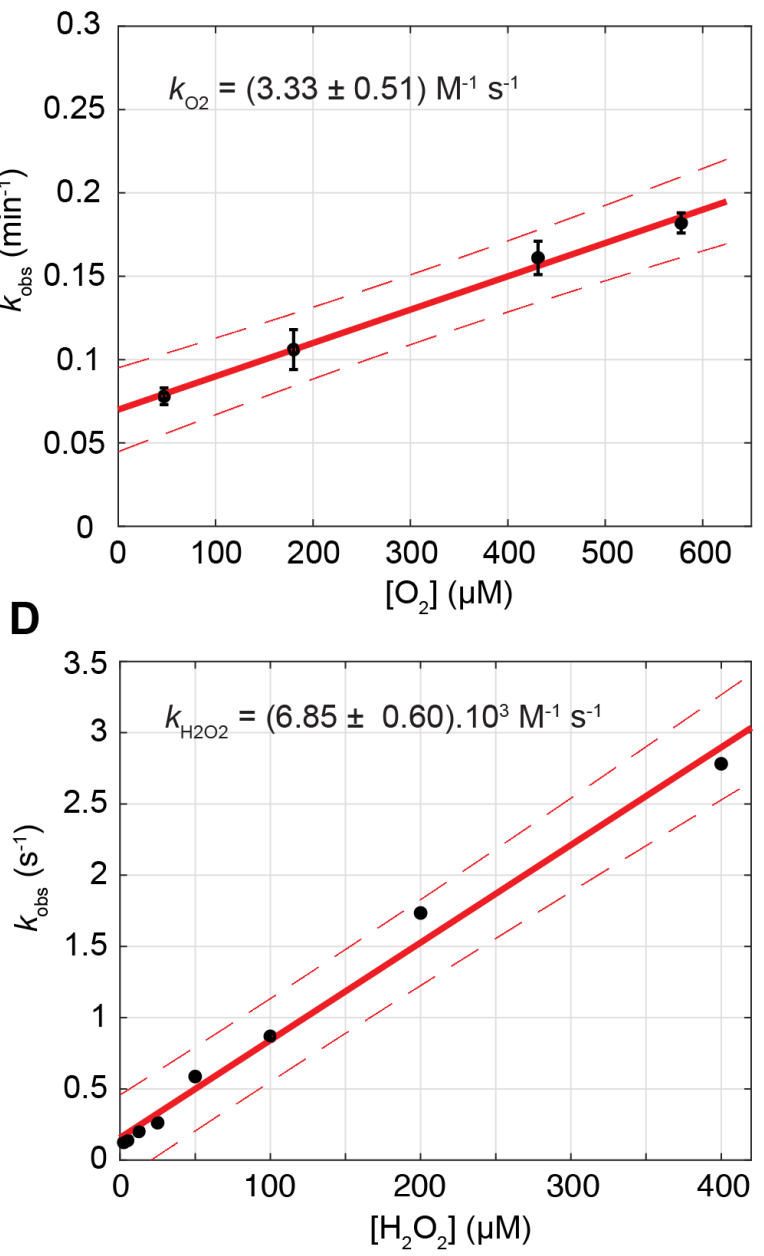

Figure 5. Single turnover re-oxidation of $\operatorname{SmAA10A-Cu(I)}$ by (A-B) $\mathrm{O}_{2}$ or (C-D) $\mathrm{H}_{2} \mathrm{O}_{2}$ in solution. SmAA10A-Cu(I) (final concentration $2 \mu \mathrm{M}$ ) was anaerobically mixed with varying concentrations of (A) $\mathrm{O}_{2}$ or (C) $\mathrm{H}_{2} \mathrm{O}_{2}$ (see color code in the figure) and the changes in fluorescence associated with re-oxidation of the $\mathrm{Cu}(\mathrm{I})$ monitored as a function of time. The reactions were carried out in sodium phosphate buffer $(50 \mathrm{mM}, \mathrm{pH} 7.0)$ at 25 ${ }^{\circ} \mathrm{C}$. Data were fit with single exponential functions (see Figures S13\&14-B and S16) to give observed rate constants $\left(k_{\mathrm{obs}}\right)$ at each co-substrate concentration and plotted versus the latter to obtain second order rate constants for (B) $\mathrm{O}_{2}$ or (D) $\mathrm{H}_{2} \mathrm{O}_{2}$. In panels A and C, for the sake of clarity, only one trace for each condition is shown (experiments were performed at least in triplicate). In panels $\mathrm{B}$ and $\mathrm{D}$, error bars show \pm s.d. ( $\mathrm{n}=3$, independent experiments), red solid lines show the best linear fit and the red dotted line the $95 \%$ confidence interval.

The reaction between $\mathrm{Sm} A A 10 A-C u(I)$ and $\mathrm{H}_{2} \mathrm{O}_{2}$ is monophasic and faster than the reaction with $\mathrm{O}_{2}$. Monitoring the single turnover reaction of anaerobic/reduced $\operatorname{SmAA} 10 \mathrm{~A}-\mathrm{Cu}(\mathrm{I})(2 \mu \mathrm{M})$ with varying concentrations of $\mathrm{H}_{2} \mathrm{O}_{2}$ showed that the enzyme underwent a change in fluorescence consistent with complete re-oxidation of the copper within seconds to milliseconds (Figure 5C). The data can be described by single exponential functions (Figure S16), indicative of a pseudo-first order reaction with respect to $\mathrm{H}_{2} \mathrm{O}_{2}$. A stoichiometry of 1:1 between $S m A A 10 A-C u(I)$ and $\mathrm{H}_{2} \mathrm{O}_{2}$ was verified (Figure S17). The fluorescence signature, together with spin trap experiments (Figure S18), indicate that the products of this reaction are $\mathrm{SmAA} 10 \mathrm{~A}-\mathrm{Cu}(\mathrm{II})$ and hydroxyl radicals $\left(80 \% \mathrm{OH}^{\bullet}\right.$ yield). Plots of the fitted pseudofirst order rate constants $k_{\mathrm{obs}}$ as a function of $\left[\mathrm{H}_{2} \mathrm{O}_{2}\right]$ could be fit to a straight line, yielding the second order rate constant $k_{\mathrm{H} 2 \mathrm{O} 2}=6.9 \times 10^{3} \mathrm{M}^{-1} \mathrm{~s}^{-1}$ (Figure 5D). Hence, for comparable concentrations of 
oxidant, the time required to convert $\mathrm{Cu}$ (I) to $\mathrm{Cu}(\mathrm{II})$ is approximately three orders of magnitude faster with $\mathrm{H}_{2} \mathrm{O}_{2}$ than with $\mathrm{O}_{2}$.

Furthermore, we explored the catalytic potential of SmAA10A-Cu(I) reacted with $\mathrm{H}_{2} \mathrm{O}_{2}$ in solution prior to addition of $\mathrm{NAG}_{6}$ substrate. If a stable reactive enzyme-oxygen intermediate formed in solution, we would expect to observe amounts of oxidized products proportional to the intermediate life-time when adding substrate after different incubation times with $\mathrm{H}_{2} \mathrm{O}_{2}$. We observed a timedependent decay in the amount of oxidized products formed (Figure S19) that corresponds to the predicted decay in amounts of available reactants (i.e. $S m A A 10 A-C u(I)$ and $\mathrm{H}_{2} \mathrm{O}_{2}$ remaining after a time-dependent fraction of $\mathrm{SmAA} 10 \mathrm{~A}-\mathrm{Cu}(\mathrm{I})$ has been consumed by the reaction with $\mathrm{H}_{2} \mathrm{O}_{2}$ in absence of substrate calculated using $\left.k_{\mathrm{H} 2 \mathrm{O} 2}=6.9 \times 10^{3} \mathrm{M}^{-1} \mathrm{~s}^{-1}\right)$. This indicates that if a productive intermediate resulting from the reaction of $S m A A 10 A-C u(I)$ with $\mathrm{H}_{2} \mathrm{O}_{2}$ would be formed in solution, then its lifetime is much shorter than the time required for a catalytic turnover in presence of substrate. Also, we show that reacting free $S m A A 10 A-C u(I)$ with $\mathrm{H}_{2} \mathrm{O}_{2}$ yields only a very low loss in activity (Figure S20). This indicates that under single turnover conditions we monitor re-oxidation of $S m A A 10 A-C u(I)$ to $\mathrm{Cu}$ (II) (see Supplementary Discussion) rather than LPMO inactivation, which thus appears to require multiple turnovers.

The substrate accelerates the reaction of $\mathrm{Sm} A A 10 A-C u(I)$ with $\mathrm{H}_{2} \mathrm{O}_{2}$, but not with $\mathrm{O}_{2} . \mathrm{QM} / \mathrm{MM}$ calculations predict that several hydrogen bonds are established between $\mathrm{H}_{2} \mathrm{O}_{2}$, the LPMO, and the substrate during $\mathrm{H}_{2} \mathrm{O}_{2}$ activation (Figure 3B), and biochemical data indicate that $\mathrm{H}_{2} \mathrm{O}_{2}$ is productively turned-over only in presence of chitin (Figure 2B). Following the same procedure outlined above, we can experimentally observe the impact of substrate on the first re-oxidation event (corresponding to steps $1 \rightarrow 3$; Figure 3C). For this, we used (NAG) 6 , which is compatible with fluorimetry experiments. Although $\mathrm{NAG}_{6}$ is a low affinity substrate under steady-state conditions (see below), we have previously shown ${ }^{27}$ that $\mathrm{NAG}_{6}$ constitutes a good proxy of $\beta$-chitin in terms of molecular interaction with the enzyme. Most importantly, under single turnover conditions, $S m A A 10 A-C u(I)$ fully engaged in $\mathrm{NAG}_{6}$ oxidation rather than non-productive deactivation pathways (Figure S21). However, we also note that the reduced LPMO can hardly catalyze more than one turnover with $\mathrm{NAG}_{6}$ as a substrate. In absence of excess of reductant, more than one turnover would require the $\mathrm{Cu}(\mathrm{I})$ form of the enzyme to be available at the end of the first catalytic cycle for the following reactions. We see that the $\mathrm{Cu}(\mathrm{I})$ species is apparently regenerated in presence of $\mathrm{NAG}_{6}$ only when low, sub-stoichiometric $\mathrm{H}_{2} \mathrm{O}_{2}$ concentrations are employed (Figure S17). This result indicates that at higher, supra-stoichiometric $\mathrm{H}_{2} \mathrm{O}_{2}$ concentrations the regenerated $\mathrm{Cu}(\mathrm{I})$ species will eventually be re-oxidized (as observed below; see Supplementary discussion). On the basis of energy profiles (Figure 3C), the first re-oxidation event is likely to determine the overall reaction rate, including the step of final re-oxidation to $\mathrm{Cu}$ (II) state observed by fluorescence. Figure 6A shows that in presence of $0.5 \mathrm{mM} \mathrm{NAG}_{6}$ re-oxidation of $\operatorname{SmAA10A-Cu(I)}$ by $\mathrm{O}_{2}$ is slightly slower. Contrarily, using $0.5 \mathrm{mM} \mathrm{NAG}_{6}$, re-oxidation of $S m \mathrm{AA} 10 \mathrm{~A}-$ $\mathrm{Cu}(\mathrm{I})$ by $\mathrm{H}_{2} \mathrm{O}_{2}$ was faster and displayed monophasic time-course profiles similar to experiments without substrate (Figure S22). The experiment was repeated with higher concentrations of $\mathrm{NAG}_{6}$ showing a proportional increase in re-oxidation rates by $\mathrm{H}_{2} \mathrm{O}_{2}$, with second order rate constant up to $k_{\mathrm{H} 2 \mathrm{O} 2}=21 \mathrm{x}$ $10^{3} \mathrm{M}^{-1} \mathrm{~s}^{-1}$ (Figure 6B). In a complementary spin-trapping experiment, we also showed that less hydroxyl radicals could be detected in presence of $\mathrm{NAG}_{6}$ (Figure S18D). 
A

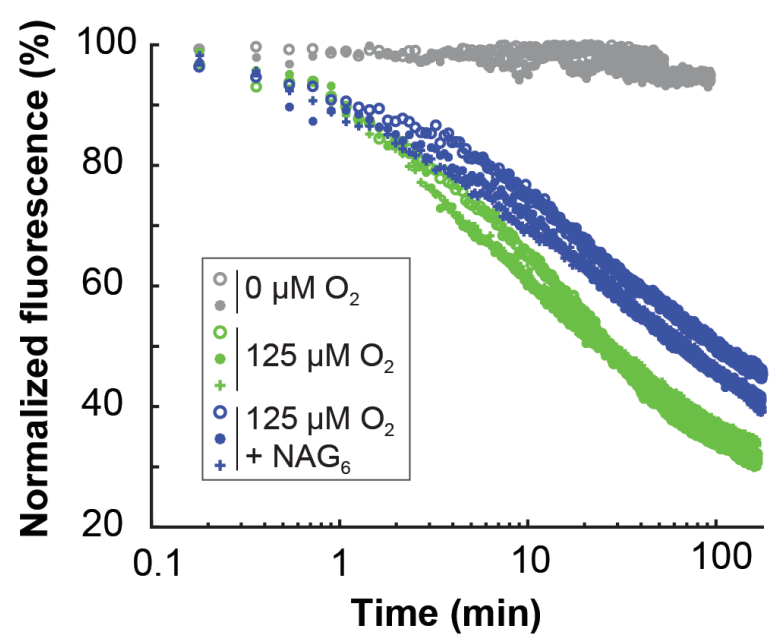

B

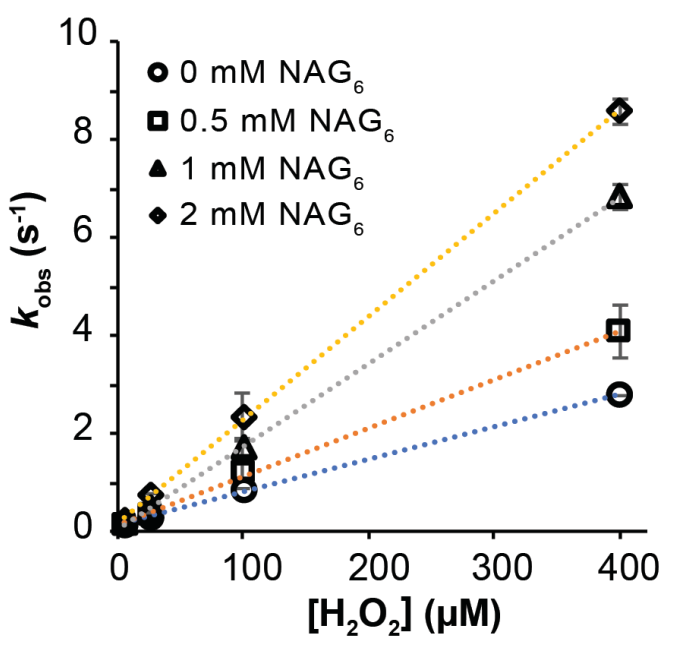

Figure 6. Re-oxidation of $S m A A 10 A-C u(I)$ by (A) $\mathrm{O}_{2}$ and (B) $\mathrm{H}_{2} \mathrm{O}_{2}$ in presence of $\mathrm{NAG}_{6}$. (A) Time-curves of re-oxidation of $\operatorname{SmAA10A-Cu}(\mathrm{I})(2 \mu \mathrm{M})$ by $125 \mu \mathrm{M} \mathrm{O}_{2}$ in presence $(0.5 \mathrm{mM})$ and absence of $\mathrm{NAG}_{6}$. All given concentrations are concentrations after mixing. (B) Second order rate plot of $\operatorname{SmAA10A-Cu(I)~re-oxidation~by~}$ $\mathrm{H}_{2} \mathrm{O}_{2}$ in presence ( 0.5 to $2 \mathrm{mM}$ ) and absence of $\mathrm{NAG}_{6}$ (see Figure $\mathbf{S 2 2}$ for example of time curves obtained with $\left.0.5 \mathrm{mM} \mathrm{NAG}_{6}\right)$. Panel A shows the traces obtained for each replicate $(\mathrm{n}=3)$ and error bars in panel B show \pm s.d. $(\mathrm{n}=3$, independent experiments).

$\mathrm{H}_{2} \mathrm{O}_{2}$ access to the active site. We have previously revealed the existence of a water tunnel, formed in the enzyme-polysaccharide complex interspace, connecting bulk solvent to the monocopper active site. ${ }^{27}$ Here, we investigated the energetics associated with $\mathrm{H}_{2} \mathrm{O}_{2}$ diffusion into the active site by $\mathrm{MD}$ simulations combined with umbrella sampling, estimating free energy profiles of $\mathrm{H}_{2} \mathrm{O}_{2}$ moving in this interspace (See Supplementary Results and Figures S1, S23 and movie S2). The free energy barrier associated with diffusion of $\mathrm{H}_{2} \mathrm{O}_{2}$ into the reaction cavity from the bulk solvent was estimated to be less than $2 \mathrm{kcal} / \mathrm{mol}$. Also, during the course of simulations, Glu60 and Asn185 appear to play a gating role, restricting $\mathrm{H}_{2} \mathrm{O}_{2}$ access to the active site cavity. In spite of the small energetic cost associated with $\mathrm{H}_{2} \mathrm{O}_{2}$ entering the confined reaction cavity, such confinement may offer greater control on reagents involved in catalysis. In agreement, we show that under steady-state conditions $S m A A 10 A$ is inefficient at consuming $\mathrm{H}_{2} \mathrm{O}_{2}$ when $\beta$-chitin is replaced by the soluble substrate $\mathrm{NAG}_{6}$ (Figure S2).

Glu60 is important for efficient peroxygenase activity. $\mathrm{QM} / \mathrm{MM}$ and $\mathrm{MD}$ calculations presented above suggest that Glu60 is involved in gating access to the active site and also constrains $\mathrm{H}_{2} \mathrm{O}_{2}$ positioning for reacting with $\mathrm{Cu}(\mathrm{I})$ (Figure 3B). This residue is structurally conserved throughout the entire LPMO superfamily, either as a glutamate or as a glutamine. ${ }^{44}$ Therefore, to probe and complement our simulations, we investigated the role of Glu60 in SmAA10A catalysis via site-directed mutagenesis. We first investigated the impact of Glu60 mutation on the apparent oxidative activity on $\beta$-chitin (Figure 7A). Figure 7A shows that mutations of Glu60 lead to a drastic decrease in product yield after $24 \mathrm{~h}$ of reaction compared to the WT enzyme (83 to $97 \%$ lower). However, in terms of initial rates (see Figure 7A inset), the impact of Glu60 mutations is less dramatic but still significant since mutants E60D, N, Q and $\mathrm{S}$ show $64,28,62$, and $48 \%$ of apparent activity relative to the wild-type enzyme, respectively. Therefore, in conditions where $\mathrm{H}_{2} \mathrm{O}_{2}$ is produced gradually in situ (e.g. Figure 2A), Glu60 appears important but not crucial for activity in the initial phase. Gradual inactivation of the LPMO, as shown by very low final yields (Figure 7A), suggests that the mutants are less efficient in consuming $\mathrm{H}_{2} \mathrm{O}_{2}$ produced in situ, which results in $\mathrm{H}_{2} \mathrm{O}_{2}$ accumulation that is known to be detrimental for LPMO stability 
in reducing conditions. ${ }^{1,34,45,46}$ This can potentially be related to poorer binding to $\beta$-chitin ${ }^{45}$ and/or, conversely, to intrinsically less efficient turnover of $\mathrm{H}_{2} \mathrm{O}_{2}$. We show that Glu60 mutants retained between 43 and $75 \%$ of the WT binding capacity in the early phase of the process (i.e. after 15 min of incubation) and between 60 and $82 \%$ at a later stage (i.e. after $4 \mathrm{~h}$ incubation) (Figure 7B and S24). In comparison, the ability of Glu60 mutants to consume $\mathrm{H}_{2} \mathrm{O}_{2}$ was much more affected (Figure 7C). Also, in absence of substrate, and under single turnover conditions, the reactivity of the free reduced Glu60 mutants with $\mathrm{H}_{2} \mathrm{O}_{2}$ was equivalent or slightly lower than that of the WT (Figure S25 and Table S5). Therefore, considering that reactivity of $\mathrm{H}_{2} \mathrm{O}_{2}$ leading to productive catalysis is three orders of magnitude faster $\left(10^{6} \mathrm{M}^{-1} \mathrm{~s}^{-1}\right)$ than the one leading to inactivation (ca. $\left.10^{3} \mathrm{M}^{-1} \mathrm{~s}^{-1}\right){ }^{34}$ the most likely scenario is that Glu60 mutations impair in first place the ability of substrate-bound LPMOs to turnover efficiently $\mathrm{H}_{2} \mathrm{O}_{2}$, which in turn leads to an accumulation of $\mathrm{H}_{2} \mathrm{O}_{2}$ inducing inactivation.

A

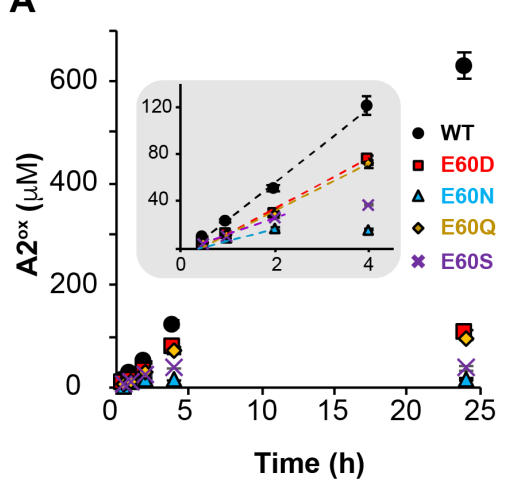

B

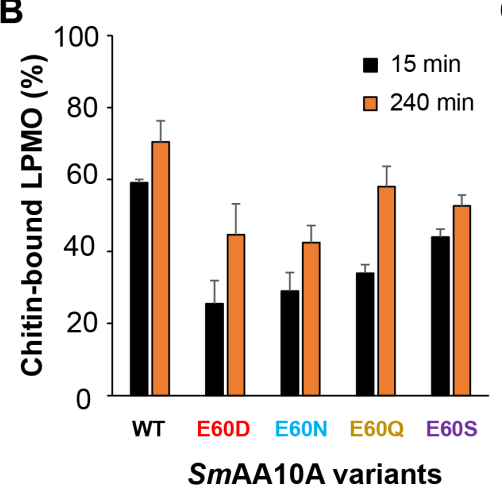

C

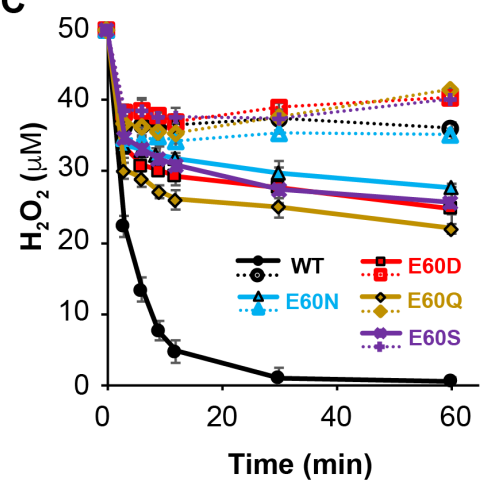

Figure 7. Biochemical characterization of $\operatorname{SmAA10A}$ and Glu60 mutants. Time-course monitoring for (A) the release of soluble chitobionic acid (A2 $\left.{ }^{\text {ox }}\right)$ from $\beta$-chitin in presence of Asc $\mathrm{A}(1 \mathrm{mM})$ and $(\mathbf{B})$ binding to $\beta$-chitin by $S m$ AA10A wildtype and mutants $(1 \mu \mathrm{M})$ (see Figure S24 for entire time-courses). The inset (grey zone) in panel A is a zoom-in view of the first 4 hours to determine the initial oxidative rate (dotted lines) of each enzyme, equal to $0.53,0.34,0.15,0.33$ and $0.26 \mathrm{~min}^{-1}$ for $S m A A 10 A-W T, E 60 D, N, Q$ and S, respectively. (C) $\mathrm{H}_{2} \mathrm{O}_{2}$ consumption $\left(50 \mu \mathrm{M}\right.$ at $\left.t_{0}\right)$ by $\operatorname{SmAA10A}$ wildtype and mutants thereof $(50 \mathrm{nM})$ in presence (solid lines) and absence (dotted lines) of $\beta$-chitin. Reactions were initiated by addition of AscA $(20 \mu \mathrm{M})$. Note that for comparative purposes the data shown here for SmAA10A-WT are a reproduction of data displayed in Figure 2B. All reactions were carried out in sodium phosphate buffer $(50 \mathrm{mM}, \mathrm{pH} 7.0)$ with $\beta$-chitin $\left(10 \mathrm{~g} . \mathrm{L}^{-1}\right)$ and incubated at $40{ }^{\circ} \mathrm{C}$ in a thermomixer $(1000 \mathrm{rpm})$. The color/symbol code is provided in each panel. Error bars show \pm s.d. $(\mathrm{n}=3$, independent experiments).

\section{DISCUSSION}

When LPMOs were identified as monocopper enzymes, it soon became apparent that they may work differently than hitherto characterized copper enzymes due to their peculiar structure and lack of additional redox-active cofactors. In this study, we present complementary experimental and computational data shedding light on the still debated ${ }^{1,46}$ LPMO reaction. Importantly, while cellulose active LPMOs have received most of the attention so far, our study proposes the first atomistic-level description of the mode of action of solid-state chitin active LPMOs, whose functionalities in Nature, notably in pathogenesis mechanisms, ${ }^{19,22,47}$ only are now being revealed.

We demonstrated by performing two complementary experiments, that not only cellulose, as shown in previous work, ${ }^{1,46}$ but also chitin oxidation by LPMOs, depends mainly (if not only) on $\mathrm{H}_{2} \mathrm{O}_{2}$ availability in standard aerobic conditions (Figure 1). Two recent computational (QM/MM) studies 
have addressed the reaction between $\mathrm{H}_{2} \mathrm{O}_{2}$ and the LPMO-bound $\mathrm{Cu}(\mathrm{I}),{ }^{32,40}$ both starting with a crystal structure of the AA9 C4-oxidizer from Lentinus similis (LsAA9A) obtained in complex with cellotriose (PDBid 5ACF). ${ }^{33}$ While we suggest that the torsional strain imposed on the $\mathrm{H}_{2} \mathrm{O}_{2}$ molecule (dihedral angle $=53^{\circ}$ ) in $S m A A 10 \mathrm{~A}$ in state 1 is important for the progress of the reaction, QM/MM models obtained by Wang et al. suggesta torsional unstrained $\mathrm{H}_{2} \mathrm{O}_{2}$ molecule (dihedral angle $=116^{\circ}$ ) that is 2.8 $\AA$ away from the active site $\mathrm{Cu}(\mathrm{I})$, hydrogen bonded to a glutamine side chain (analogous to the SmAA10A Glu60) and a water molecule. ${ }^{32}$ Differences in the second sphere environment between AA10 and AA9s may explain such difference. However, we also observe that the QM region in both QM/MM studies on LsAA9A is composed of different residues, which we think impacts significantly the outcome of calculations (see Supplementary Discussion and Figure S26). Wang et al. identified a transition state akin to state 2 presented in this work with an energy barrier of $5.8 \mathrm{kcal} \mathrm{mol}^{-1}$ (B3LYP). This value is lower than the one calculated for our SmAA10A-chitin model $\left(12.8 \mathrm{kcal} \mathrm{mol}^{-1}\right.$ (B3LYP) and $8.6 \mathrm{kcal}$ $\mathrm{mol}^{-1}$ (TPSSh)). The two previous computational studies suggest substrate $\mathrm{H}$-abstraction energy barriers (states 5 to 6; Figure 3) of $5.5 \mathrm{kcal} \mathrm{mol}^{-1}(\mathrm{~B} 3 \mathrm{LYP})^{32}$ and $16.5 \mathrm{kcal} \mathrm{mol}^{-1}$ (TPSS) ${ }^{40}$ whereas we obtained values of $13.0 \mathrm{kcal} \mathrm{mol}^{-1}$ (B3LYP) and $10.6 \mathrm{kcal} \mathrm{mol}^{-1}$ (TPSSh) for the SmAA10A-chitin model. Not only the use of different DFT-functionals may explain the discrepancies observed between the two different $L s$ AA9A-cellotriose models ${ }^{32,40}$, but it is also apparent that the cellotriose ligand has been repositioned during model preparation, resulting in complexes different from the crystal structure (Figure S26A).

While Wang et al. ${ }^{32}$ report that all the steps of the LPMO catalyzed reaction take place on a singlet energy surface, Hedegård \& Ryde ${ }^{32,40}$ identify two intermediates that have triplet ground states, those resembling states 5 and 7 in this work. Although the QM/MM/MD simulation (Movie S1) of the SmAA10A-chitin model, that provided the underpinning molecular geometries for our mechanistic approach, also progressed on a singlet surface, subsequent refinement provided more details. We found that state $\mathbf{4}$ and $\mathbf{5}$ have triplet ground states, and this was confirmed by unrestricted corresponding orbital (UCO) analysis (zero UCO overlap). A previous study, employing a higher level of theory (CASSFC/CASPT2) than DFT, reported that the copper-oxyl complexes of various (not LPMO related) model compounds had triplet ground states, ${ }^{48}$ supporting our findings for state 5. Similarly to some studies on other metalloenzymes, ${ }^{2}$ our results indicate that LPMOs-catalyzed chemistry would rely on spin-crossover transitions (here in a singlet-triplet-singlet sequence) to reduce energetic barriers of reactions involving unpaired electrons. Despite differences in TS energy barriers and spin states, our study together with work on LsAA9A-cellotriose models ${ }^{32,40}$ point collectively towards a LPMO peroxygenase reaction that is thermodynamically feasible and kinetically more favorable than a monooxygenase reaction, this for different families of LPMO and types of substrate.

The nature of the rate limiting step of LPMO catalysis, and the order of catalytic events are not settled. So far, only one study has estimated the overall steady-state kinetic parameters of LPMO catalysis in presence of $\mathrm{H}_{2} \mathrm{O}_{2}$, precisely for $\operatorname{SmAA} 10 \mathrm{~A}\left(k_{\mathrm{cat}}=6.7 \mathrm{~s}^{-1} K_{\mathrm{M}}\right.$, $\left.\mathrm{H} 2 \mathrm{O} 2 \sim 3 \mu \mathrm{M}\right) .{ }^{34}$ For comparative purposes, the few available kinetic studies carried out under $\mathrm{O}_{2}$ conditions (i.e. no added $\mathrm{H}_{2} \mathrm{O}_{2}$ ) reported catalytic efficiencies on soluble substrates more than two orders of magnitude lower than that of the peroxygenase reaction. $^{33,49}$

Here, we took advantage of a) the fluorophore-properties of the LPMO-Cu(I)/Cu(II) redox couple previously described by Bissaro et al., ${ }^{43}$ and b) an experimental approach where we worked with isolated species to dissect reduction and re-oxidation catalytic events. Our data indicate that the reduction rate is unlikely to be a rate-limiting event, provided that sufficient amount of reducing power is present in the reaction. Indeed, using AscA $>20 \mu \mathrm{M}$ (the lowest AscA concentration employed here) would yield rates $>8 \mathrm{~s}^{-1}$, which is slightly faster than the $k_{\text {cat }}$ determined for SmAA10A. ${ }^{34}$ Under standard 
aerobic steady-state conditions, the reduction step is definitely not rate-limiting since $\mathrm{mM}$ concentrations of reductant are usually employed. ${ }^{16}$ The reduced $S m \mathrm{AA} 10 \mathrm{~A}-\mathrm{Cu}(\mathrm{I})$ is the precursor for all suggested LPMO catalytic pathways. ${ }^{1,23,24}$ The facts that the LPMO-Cu(I) form binds more strongly to substrates than LPMO-Cu(II) ${ }^{37,49,50}$ and that access to the active site is severely hindered when the LPMO is bound to substrate ${ }^{27}$ suggest that LPMO reduction occurs in solution. In agreement, our stopped-flow experiments indicate that $S m A A 10 A$ reduction is not significantly influenced by the presence of carbohydrate substrate(Figure S12). Furthermore, our data on the lifetime of LPMO-Cu(I) exposed to $\mathrm{H}_{2} \mathrm{O}_{2}$ (Figure S19) show that productive catalysis with $\mathrm{H}_{2} \mathrm{O}_{2}$ (i.e. peroxygenation) most certainly occur when the reduced enzyme is pre-bound to the carbohydrate substrate. Nevertheless, depending on the rate of association to substrate, the reduced LPMO active site will be exposed to oxidants such as $\mathrm{O}_{2}$ and $\mathrm{H}_{2} \mathrm{O}_{2}$ before it settles on the carbohydrate surface. Thus, as an initial experiment, $\mathrm{O}_{2}$ and $\mathrm{H}_{2} \mathrm{O}_{2}$ reactivity with $S m A A 10 A-C u(I)$ was monitored in absence of substrate. The second order rate constant for the reaction with $\mathrm{O}_{2}, k_{\mathrm{O} 2}=3.33 \mathrm{M}^{-1} \mathrm{~s}^{-1}$, is surprisingly low (see discussion below), a typical reaction proceeding over several minutes with an enzyme: $\mathrm{O}_{2}$ molar ratio of 1:100. This is in striking contrast with what has been reported for an AA9 $\mathrm{C} 1 / \mathrm{C} 4$ oxidizer from Thermoascus aurantiacus ( $T a$ AA9A), that was shown to be re-oxidized in seconds $\left(\sim 0.15 \mathrm{~s}^{-1}\right)$ at an enzyme: $\mathrm{O}_{2}$ molar ratio of ca. $1: 1{ }^{38}$ It is a possibility that this difference in rates underpins a more general, fundamental difference between AA9s and AA10s with respect to $\mathrm{O}_{2}$ activation pathways. In the frame of the Marcus theory, we can predict the rate of outer-sphere electron transfer between $\mathrm{LPMO}-\mathrm{Cu}(\mathrm{I})$ and $\mathrm{O}_{2}$, as outlined by Kjaergaard et al. ${ }^{38}$ (See Supporting discussion for details). Thereby, we estimate an electron transfer (ET) rate $k_{\mathrm{ET}, 02}=3.39 \mathrm{M}^{-1} \mathrm{~s}^{-1}$, a value remarkably similar to the experimentally determined $k_{\mathrm{O} 2}=3.33$ $\mathrm{M}^{-1} \mathrm{~s}^{-1}$. This result implies that reduction of $\mathrm{O}_{2}$ would be subject to an outer-sphere reduction, in contrast to an inner sphere reduction suggested by data on $\mathrm{TaAA} 9 \mathrm{~A} .{ }^{38}$ An outer-sphere reduction entails that $\mathrm{O}_{2}$ would be first reduced in a "pre-bound" configuration and only then the resulting $\mathrm{O}_{2}{ }^{\circ-}$ and $\mathrm{Cu}$ (II) would form a covalent bond. Such pre-bound $\mathrm{O}_{2}$ has been suggested by neutron protein crystallography and DFT calculations for an AA9, ${ }^{51}$ but not for any AA10 yet.

Comparing the $k_{\mathrm{O} 2}$ value of SmAA10A with other "classical" monooxygenases provides some interesting insights. Indeed, bimolecular rate constants for re-oxidation by $\mathrm{O}_{2}$ are several orders of magnitude higher $\left(10^{5}-10^{7} \mathrm{M}^{-1} \mathrm{~s}^{-1}\right)$ for bi-nuclear copper enzymes such as tyrosinases ${ }^{2}$ and dopamine monooxygenase ${ }^{52}$, monocopper amine oxidase ${ }^{53}$ and galactose oxidases, ${ }^{54}$ as well as some multi-copper laccases. ${ }^{55,56}$ In light of this comparison, together with steady-state kinetics studies ${ }^{34}$ and QM/MM results presented here, we conclude that $S m A A 10 \mathrm{~A}$ has not been evolved to act as a $\mathrm{O}_{2}$-using oxygenase.

Regarding the reaction of $S m A A 10 A-C u(I)$ with $\mathrm{H}_{2} \mathrm{O}_{2}$, we determined a second order rate constant of $6.85 \times 10^{3} \mathrm{M}^{-1} \mathrm{~s}^{-1}$, which is three orders of magnitude faster than the corresponding reaction with $\mathrm{O}_{2}$. Also, in the second order rate constant plots (Figure 5B\&D), the y intercept is close to zero when using $\mathrm{H}_{2} \mathrm{O}_{2}$ as oxidant but not when using $\mathrm{O}_{2}$. This is indicative of a reaction of $\operatorname{SmAA} 10 \mathrm{~A}-\mathrm{Cu}(\mathrm{I})$ with $\mathrm{H}_{2} \mathrm{O}_{2}$ that is mainly irreversible while it denotes a certain extent of reversibility with $\mathrm{O}_{2}$. The reaction with $\mathrm{H}_{2} \mathrm{O}_{2}$ resembles a Fenton reaction, generating highly reactive hydroxyl radicals (Figure S18) while consuming equimolar amounts of $S m A A 10 A-C u(I)$ and $\mathrm{H}_{2} \mathrm{O}_{2}$ (Figure S17). We have no indications that a $\mathrm{Cu}$-oxyl intermediate is formed in the reaction between $S m A A 10 A-C u(I)$ and $\mathrm{H}_{2} \mathrm{O}_{2}$ in solution, and we could not detect any long-lived $\mathrm{Cu}$-oxyl intermediate that could bind and cleave substrate after it was formed (Figure S19). Remarkably, it appears that the reaction between SmAA10A$\mathrm{Cu}(\mathrm{I})$ and $\mathrm{H}_{2} \mathrm{O}_{2}$ is slower in solution than in presence of substrate. If we compare the $\mathrm{V}_{\max }$ determined by Kuusk et al..$^{34}$ (at saturating $\left[\mathrm{H}_{2} \mathrm{O}_{2}\right]$ of $20 \mu \mathrm{M}$ ) with the reaction rate calculated from the second order rate constant $k^{\mathrm{H} 2 \mathrm{O} 2}$ determined here, it appears that the reaction with $\mathrm{H}_{2} \mathrm{O}_{2}$ is accelerated by about 50 times in presence of substrate $\left(k_{\text {cat }} \times[\mathrm{E}] / k^{\mathrm{H} 2 \mathrm{O} 2} \times[\mathrm{E}] \times\left[\mathrm{H}_{2} \mathrm{O}_{2}\right]=6.7 \mathrm{~s}^{-1} / 6.85 \times 10^{3} \mathrm{M}^{-1} \mathrm{~s}^{-1} \times 20 \mu \mathrm{M}=\right.$ 48.9). Repeating single turnover re-oxidation experiments in presence of $\mathrm{NAG}_{6}$ showed that re- 
oxidation by $\mathrm{O}_{2}$ was slowed down whereas, re-oxidation by $\mathrm{H}_{2} \mathrm{O}_{2}$ was boosted in a $\mathrm{NAG}_{6}$ concentrationdependent manner. Considering these observations in light of the computational data that predict steric clashes between the substrate and superoxide (Figure S9), we may speculate that $\mathrm{O}_{2}$ and $\mathrm{NAG}_{6}$ compete for the active site. On the other hand, the accelerated re-oxidation observed with $\mathrm{H}_{2} \mathrm{O}_{2}$ and $\mathrm{NAG}_{6}$ indicate that oxidative cleavage of insoluble chitin and $\mathrm{NAG}_{6}$ follow the same reaction path. In our QM/MM models, the roles of interactions with the substrate appear to be threefold along the reaction coordinates : (i) together with Glu60, the substrate $\mathrm{H}$-bond assists $\mathrm{H}_{2} \mathrm{O}_{2}$ molecule positioning in the reaction cavity (state 1; Figure 3B) and (ii) helps stabilizing the reactive "precision-guided HO" (states 2 - 4); (iii) these interactions seem to position the $\mathrm{H}_{2} \mathrm{O}_{2}$ derived water molecule that contributes with a $\mathrm{H}$-bond to the reactive species in the final stages of the reaction mechanism (states 5-9) (Figure S9). Thereby, we suggest a substrate-assisted mechanism in which substrate H-bond donation facilitates the initial one-electron reduction of $\mathrm{H}_{2} \mathrm{O}_{2}$ in the SmAA10A-chitin complex and thus results in an increased reaction rate in presence of substrate, in agreement with ternary complex formation predicted by steadystates kinetic. ${ }^{34}$ The cellulose "analog" of the chitin amide group that could act as hydrogen bond donor is the 2'-OH moiety, which is hydrogen bonded to the adjacent chain glucose residue and not readily available for $\mathrm{H}$-bonding to $\mathrm{H}_{2} \mathrm{O}_{2}$. It is not known if the presence of substrate increases the reaction rate of AA9 enzymes with $\mathrm{H}_{2} \mathrm{O}_{2}$. When the SmAA10A Glu60 residue was mutated to Gln, Asp, Asn and Ser, the ability of the $\mathrm{Cu}(\mathrm{I})$ site to react with $\mathrm{H}_{2} \mathrm{O}_{2}$ in absence of substrate was retained (Table S3). Nevertheless, the catalytic efficiencies of these mutants with insoluble chitin substrate decreased considerably (Figure 7), indicating that formation of a productive ternary complex was obstructed by altering the $\mathrm{H}_{2} \mathrm{O}_{2}$ interacting environment in the reaction cavity.

After it was suggested that $\mathrm{H}_{2} \mathrm{O}_{2}$ is the relevant co-substrate for LPMOs, ${ }^{1}$ only one hypothesis relating to the rate limiting step of the reaction has appeared in the literature. In their hypothesis, Wang et al. proposed that (non-enzymatic) hydrolysis of the hydroxylated carbohydrate, i.e. state $\mathbf{9}$ in this work, is the rate limiting step. The rationale behind this suggestion is that they found, by computational methods, a high transition state energy barrier for the glycosidic bond cleavage reaction $(18.2 \mathrm{kcal} / \mathrm{mol})$ that coincided with $L s$ AA9A catalytic constant $\left(k_{\text {cat }}=0.11 \mathrm{~s}^{-1}\right)$ determined under ambient $\mathrm{O}_{2}$ (i.e. uncontrolled, limiting $\mathrm{H}_{2} \mathrm{O}_{2}$ ) conditions. In spite of limitations when attempting to relate energy barriers to catalytic constants (see Supplementary discussion), it is a possibility, awaiting experimental validation, that such hypothesis holds for LPMOs acting on soluble substrates and using $\mathrm{O}_{2}$ as cosubstrate. For polysaccharide-active LPMOs, both from AA9 and AA10 families, there are multiple experimental evidences that the apparent LPMO rate, under stationary conditions (i.e. no excess of $\mathrm{H}_{2} \mathrm{O}_{2}$ ), is limited by the rate of in situ production or supply of $\mathrm{H}_{2} \mathrm{O}_{2}{ }^{1,34,46,57}$ Therefore, in biologicallyrelevant settings, where low steady-state concentrations of $\mathrm{H}_{2} \mathrm{O}_{2}$ are expected, LPMO catalysis will be mainly driven by the probability of encounter between $\mathrm{H}_{2} \mathrm{O}_{2}$ and substrate-bound pre-reduced LPMOs. Under $\mathrm{H}_{2} \mathrm{O}_{2}$ saturating conditions, it is not likely that the LPMO-Cu(II) to LPMO-Cu(I) reduction (Figure 8, step 1) is the rate limiting step when sufficient amounts of reductant are available (see above). As summarized in Figure 8, we propose the following order of events for the LPMO peroxygenase reaction. Step 1: the substrate-dissociated enzyme is reduced via close contact between the enzyme copper site and the reducing species. Step 2: the LPMO binds in a specific manner, positioned to facilitate formation of a ternary complex. Step 3: $\mathrm{H}_{2} \mathrm{O}_{2}$ diffuses freely into the reaction cavity via a tunnel access and is guided into a strained position, optimal for $\mathrm{H}_{2} \mathrm{O}_{2}$ reduction, by specific hydrogen bonding interactions. Steps 4-7: the reaction progress as indicated by states 1 to 9 described in this work. Steps 8 and 9: glycosidic bond cleavage (via elimination reaction) and enzyme dissociation from the substrate occur in an order that remains to be clarified. Steps 10-10': in a substrate-free case, the LPMO can engage into inactivation processes provided that $\mathrm{H}_{2} \mathrm{O}_{2}$ accumulated in the system. It is interesting to note that $k_{\mathrm{H} 2 \mathrm{O} 2}$ is nearly one order of magnitude higher than the apparent inactivation rate previously 
determined in presence of excess of reductant $\left(10^{3} \mathrm{M}^{-1} \mathrm{~s}^{-1}\right),{ }^{34}$ indicating that this reaction (steps 10 )is not the rate limiting factor in the inactivation process. Our data also indicate that multiple turnovers are required to inactivate the enzyme (Figure S20). Steps 11-11': Substrate-free LPMOs can also engage into $\mathrm{H}_{2} \mathrm{O}_{2}$ production pathway. In the latter, the reactivity of $S m \mathrm{AA} 10 \mathrm{~A}-\mathrm{Cu}(\mathrm{I})$ with $\mathrm{O}_{2}$ seems to be the rate-limiting step since the second order rate of $3.3 \mathrm{M}^{-1} \mathrm{~s}^{-1}$ yields a turnover of $8.10^{-4} \mathrm{~s}^{-1}$ at ambient $\left[\mathrm{O}_{2}\right]$, a value strikingly similar to the apparent $\mathrm{H}_{2} \mathrm{O}_{2}$ production rate. ${ }^{16}$

The experimental conditions of the LPMO reaction will affect the outcome of the chain of events. With low affinity substrates and high concentrations of $\mathrm{H}_{2} \mathrm{O}_{2}$ a single turnover may be observed. At optimal conditions, where reducing equivalents and $\mathrm{H}_{2} \mathrm{O}_{2}$ are delivered in a timely fashion in presence of a suitable substrate, multiple turnovers are expected before the enzyme is inactivated. ${ }^{57}$ The proposed substrate-assisted mechanism provides a competitive advantage to polysaccharide-bound LPMOs for turning over $\mathrm{H}_{2} \mathrm{O}_{2}$ compared to the reaction with $\mathrm{H}_{2} \mathrm{O}_{2}$ in solution that leads to enzyme inactivation via formation of hazardous hydroxyl radicals

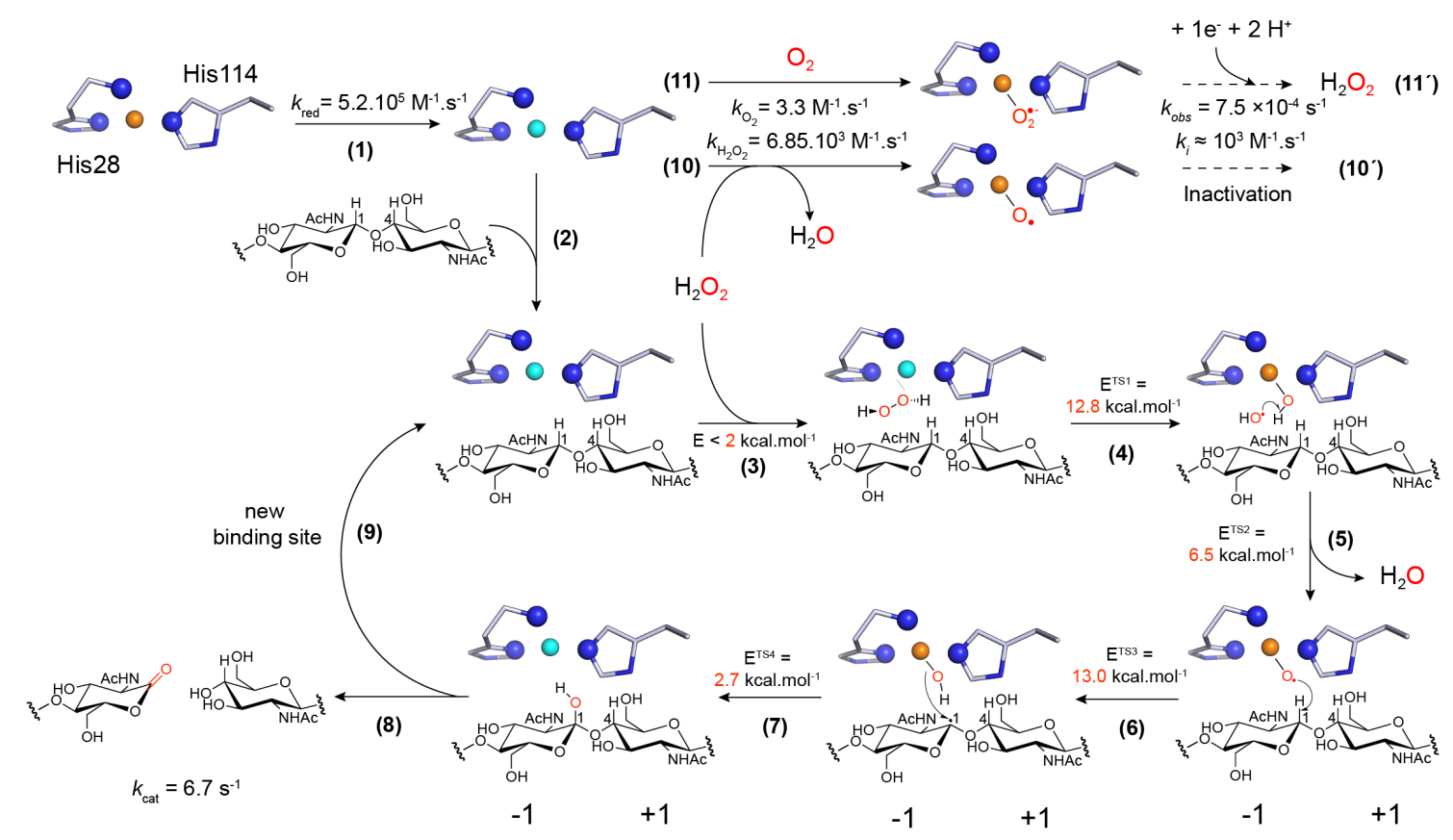

Figure 8. Proposed molecular mechanism of chitin oxidation by $\operatorname{SmAA10A}$ and associated rate constants or energy barriers. Step 1: the resting LPMO-Cu(II) is reduced to the LPMO-Cu(I) active state $\left(4.23 \times 10^{5} \mathrm{M}^{-1} \mathrm{~s}^{-1}\right.$; i.e. $423 \mathrm{~s}^{-1}$ or $8.5 \mathrm{~s}^{-1}$ when using $1 \mathrm{mM}$ or $20 \mu \mathrm{M}$ AscA, respectively). Step 2: polysaccharide binding. Step 3: $\mathrm{H}_{2} \mathrm{O}_{2}$ diffusion to the active site cavity through a tunnel access. Step 4: reaction of $\mathrm{H}_{2} \mathrm{O}_{2}$ with $\mathrm{Cu}(\mathrm{I})$ inducing homolytic bond cleavage yielding a $\mathrm{Cu}(\mathrm{II})-\mathrm{OH}$ species and a hydroxyl radical. Step 5: the hydroxyl radical reacts with $\mathrm{Cu}(\mathrm{II})-\mathrm{OH}$ yielding a water molecule and a $[\mathrm{CuO}]^{+}$intermediate. Step 6: $[\mathrm{CuO}]^{+}$catalyzes HAA from the substrate. Step 7: hydroxylation of the C1 carbon via oxygen-rebound mechanism. ${ }^{29}$ Step 8: The hydroxylated product undergoes an elimination reaction, ${ }^{26}$ suggested to be enzyme independent, ${ }^{32}$ inducing glycosidic bond cleavage. Step 9: The LPMO-Cu(I) can enter a new catalytic cycle. Step 10: substrate-free LPMO-Cu(I) can react with $\mathrm{H}_{2} \mathrm{O}_{2}\left(6.85 \times 10^{3} \mathrm{M}^{-1} \mathrm{~s}^{-1}\right)$ leading eventually, after multiple turnovers, to enzyme inactivation (step $\mathbf{1 0}^{\prime}$, ca. $\left.10^{3} \mathrm{M}^{-1} \mathrm{~s}^{-1}\right)^{34}$. Step 11: The LPMO-Cu(I) can also react with $\mathrm{O}_{2}\left(3.3 \mathrm{M}^{-1} \mathrm{~s}^{-1}\right.$; i.e. $8.10^{-4} \mathrm{~s}^{-1}$ at $250 \mu \mathrm{M}$ (atmospheric)

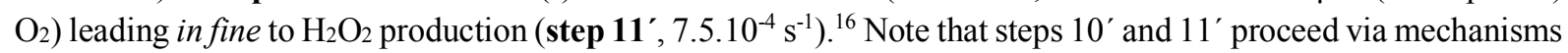
that remain to be fully elucidated. 


\section{CONCLUSIONS}

We have presented how LPMOs can harness the intrinsic oxidative power of $\mathrm{H}_{2} \mathrm{O}_{2}$, in a controlled and substrate-assisted manner to oxidize crystalline chitin. Our study reveals how unique LPMO chemistry is, since relying on the formation of a confined active site reaction cavity upon association of the enzyme with the polysaccharide. Resembling what we first described as an enzyme-guided Fenton reaction, ${ }^{28}$ the formation of a ternary complex provides the adapted environment to allow efficient $\mathrm{H}_{2} \mathrm{O}_{2}$ reduction and generation of a "precision-guided $\mathrm{HO}^{\text {", }}$ leading to a reactive $[\mathrm{CuO}]^{+}$core. In the context of frontier molecular orbital theory, we presented in great details the electronic features of the reactivity of $\mathrm{H}_{2} \mathrm{O}_{2}$ with $\mathrm{LPMO}-\mathrm{Cu}(\mathrm{I})$, which will assist future spectroscopic studies. We have also shown the occurrence of spin crossover events along the reaction coordinates, suggesting that the multiplicity can be tuned to cope with energetic barriers of reactions involving unpaired electrons. We reported for the first time single turnover kinetics of reactions of LPMO-Cu(I) with $\mathrm{O}_{2}$ and $\mathrm{H}_{2} \mathrm{O}_{2}$, indicating, together with steadystate kinetics and computational simulations, that the use of $\mathrm{O}_{2}$ as co-substrate by $S m$ AA10A to oxidize chitin is very unlikely and supporting the peroxygenase paradigm. Questioning the universality of this mechanism across LPMOs families will no doubt be a topic of intense investigations for the coming years.

We foresee that the molecular basis of this unusual, copper-based chemistry catalyzed by LPMOs will inspire and assist the design of new model complexes for oxy-functionalization of inert C$\mathrm{H}$ bonds. Furthermore, witnessing strong indications of the chitinolytic role of LPMOs in pathogenesis and defense mechanisms, we believe our study will set foundations for a better understanding of these biologically important questions.

\section{ASSOCIATED CONTENT}

Supporting information. The supporting information contains supplemental Figures S1-26, Tables S1-4, Scheme S1, Movie S1 and Movie S2.

\section{AUTHORS INFORMATION}

\section{Corresponding authors}

*asmund.rohr@nmbu.no,jennifer.dubois1@montana.edu

\section{ORCID}

Bastien Bissaro: 0000-0001-8354-3892

Vincent Eijsink: 0000-0002-9220-8743

Gregg Beckham: 0000-0002-3480-212X

Jennifer DuBois: 0000-0001-5593-3391

Åsmund K. Røhr: 0000-0002-4956-4865

\section{Conflicts of interest}

The authors declare no conflicts of interest with the contents of this article. 


\author{
Abbreviations \\ The abbreviations used are: \\ AscA: Ascorbic acid \\ AR : AmplexRed $\AA$ \\ $\mathrm{A} 2^{\mathrm{ox}}$ : Chitobionic acid or GlcNAcGlcNAc1A \\ GH: Glycoside hydrolases \\ HAA: Hydrogen atom abstraction \\ HRP: Horseradish peroxidase \\ LPMO: Lytic polysaccharide monooxygenases \\ LsAA9A: LPMO9 from Lentinus similis \\ MD: Molecular dynamics \\ MM: Molecular mechanics \\ $\mathrm{NAG}_{6}:$ Hexa- $N$-acetyl-chitohexaose \\ NEB : Nudged elastic band \\ QM : Quantum mechanics \\ SmAA10A (or CBP21): LPMO10 from Serratia marcescens \\ SmGH20: Chitobiase from Serratia marcescens \\ EPR: Electron paramagnetic resonance \\ SOMO: single occupied molecular orbital \\ HOMO: highest occupied molecular orbital \\ LUMO: Lowest unoccupied molecular orbital
}

\title{
ACKNOWLEDGMENT
}

This work was supported by the Research Council of Norway grants 240967 ( $\AA \mathrm{KR}$ ) and 269408 (VE), and National Science Foundation grant MCB1715176 (JB). Computational work was performed on the Abel Cluster, owned by the University of Oslo, and the Norwegian metacenter for High Performance Computing (NOTUR) and the Extreme Science and Engineering Discovery Environment (XSEDE), which is supported by National Science Foundation grant number ACI-1548562, through allocation TGMCB090159 to GTB. This work authored in part by Alliance for Sustainable Energy, LLC, the manager and operator of the National Renewable Energy Laboratory for the U.S. Department of Energy (DOE) under Contract No. DE-AC36-08GO28308. Funding was provided to GTB by the U.S. Department of Energy Office of Energy Efficiency and Renewable Energy the Bioenergy Technologies Office.

\section{REFERENCES}

(1) Bissaro, B.; Røhr, Å. K.; Müller, G.; Chylenski, P.; Skaugen, M.; Forsberg, Z.; Horn, S. J.; Vaaje-Kolstad, G.; Eijsink, V. G. H. Nat. Chem. Biol. 2017, 13 (10), 1123.

(2) Solomon, E. I.; Heppner, D. E.; Johnston, E. M.; Ginsbach, J. W.; Cirera, J.; Qayyum, M.; KieberEmmons, M. T.; Kjaergaard, C. H.; Hadt, R. G.; Tian, L. Chem. Rev. 2014, 114 (7), 3659.

(3) Vaaje-Kolstad, G.; Westereng, B.; Horn, S. J.; Liu, Z.; Zhai, H.; Sørlie, M.; Eijsink, V. G. H. Science (80.). 2010, 330 (6001), 219.

(4) Quinlan, R. J.; Sweeney, M. D.; Lo Leggio, L.; Otten, H.; Poulsen, J.-C. N.; Johansen, K. S.; Krogh, K. B. R. M.; Jorgensen, C. I.; Tovborg, M.; Anthonsen, A.; Tryfona, T.; Walter, C. P.; Dupree, P.; Xu, F.; Davies, G. J.; Walton, P. H. Proc. Natl. Acad. Sci. 2011, 108 (37), 15079.

(5) Forsberg, Z.; Vaaje-kolstad, G.; Westereng, B.; Bunsæ, A. C.; Stenstrøm, Y.; Mackenzie, A.; Sørlie, M.; Horn, S. J.; Eijsink, V. G. H. Protein Sci. 2011, 20 (9), 1479.

(6) Langston, J. A.; Shaghasi, T.; Abbate, E.; Xu, F.; Vlasenko, E.; Sweeney, M. D. Appl. Environ. Microbiol. 2011, 77 (19), 7007.

(7) Frommhagen, M.; Sforza, S.; Westphal, A. H.; Visser, J.; Hinz, S. W. A.; Koetsier, M. J.; Van Berkel, W. J. H.; Gruppen, H.; Kabel, M. A. Biotechnol. Biofuels 2015, 8 (1), 101.

(8) Couturier, M.; Ladevèze, S.; Sulzenbacher, G.; Ciano, L.; Fanuel, M.; Moreau, C.; Villares, A.; Cathala, 
B.; Chaspoul, F.; Frandsen, K. E.; Labourel, A.; Herpoël-Gimbert, I.; Grisel, S.; Haon, M.; Lenfant, N.; Rogniaux, H.; Ropartz, D.; Davies, G. J.; Rosso, M. N.; Walton, P. H.; Henrissat, B.; Berrin, J. G. Nat. Chem. Biol. 2018, 14 (3), 306.

(9) Villares, A.; Moreau, C.; Bennati-Granier, C.; Garajova, S.; Foucat, L.; Falourd, X.; Saake, B.; Berrin, J. G.; Cathala, B. Sci. Rep. 2017, 7, 40262.

(10) Vermaas, J. V.; Crowley, M. F.; Beckham, G. T.; Payne, C. M. J. Phys. Chem. B 2015, 119 (20), 6129.

(11) Eibinger, M.; Sattelkow, J.; Ganner, T.; Plank, H.; Nidetzky, B. Nat. Commun. 2017, 8 (1), 894.

(12) Harris, P. V.; Welner, D.; McFarland, K. C.; Re, E.; Navarro Poulsen, J. C.; Brown, K.; Salbo, R.; Ding, H.; Vlasenko, E.; Merino, S.; Xu, F.; Cherry, J.; Larsen, S.; Lo Leggio, L. Biochemistry 2010, 49 (15), 3305.

(13) Payne, C. M.; Knott, B. C.; Mayes, H. B.; Hansson, H.; Himmel, M. E.; Sandgren, M.; Ståhlberg, J.; Beckham, G. T. Chemical Reviews. February 11, 2015, pp 1308-1448.

(14) Floudas, D.; Binder, M.; Riley, R.; Barry, K.; Blanchette, R. A.; Henrissat, B.; Martínez, A. T.; Otillar, R.; Spatafora, J. W.; Yadav, J. S.; Aerts, A.; Benoit, I.; Boyd, A.; Carlson, A.; Copeland, A.; Coutinho, P. M.; De Vries, R. P.; Ferreira, P.; Findley, K.; Foster, B.; Gaskell, J.; Glotzer, D.; Górecki, P.; Heitman, J.; Hesse, C.; Hori, C.; Igarashi, K.; Jurgens, J. A.; Kallen, N.; Kersten, P.; Kohler, A.; Kües, U.; Kumar, T. K. A.; Kuo, A.; LaButti, K.; Larrondo, L. F.; Lindquist, E.; Ling, A.; Lombard, V.; Lucas, S.; Lundell, T.; Martin, R.; McLaughlin, D. J.; Morgenstern, I.; Morin, E.; Murat, C.; Nagy, L. G.; Nolan, M.; Ohm, R. A.; Patyshakuliyeva, A.; Rokas, A.; Ruiz-Dueñas, F. J.; Sabat, G.; Salamov, A.; Samejima, M.; Schmutz, J.; Slot, J. C.; John, F. S.; Stenlid, J.; Sun, H.; Sun, S.; Syed, K.; Tsang, A.; Wiebenga, A.; Young, D.; Pisabarro, A.; Eastwood, D. C.; Martin, F.; Cullen, D.; Grigoriev, I. V.; Hibbett, D. S. Science (80-. ). 2012, 336 (6089), 1715.

(15) Müller, G.; Várnai, A.; Johansen, K. S.; Eijsink, V. G. H.; Horn, S. J. Biotechnol. Biofuels 2015, 8 (187).

(16) Bissaro, B.; Varnai, A.; Røhr, Å. K.; Eijsink, V. G. H. Microbiol. Mol. Biol. Rev. $2018,4$.

(17) Cannella, D.; Hsieh, C. W. C.; Felby, C.; Jørgensen, H. Biotechnol. Biofuels 2012, 5 (1), 26.

(18) Johansen, K. S. Biochem. Soc. Trans. 2016, 44 (1), 143.

(19) Wong, E.; Vaaje-Kolstad, G.; Ghosh, A.; Hurtado-Guerrero, R.; Konarev, P. V.; Ibrahim, A. F. M.; Svergun, D. I.; Eijsink, V. G. H.; Chatterjee, N. S.; van Aalten, D. M. F. PLoS Pathog. 2012, 8 (1), e1002373.

(20) Loose, J. S. M.; Forsberg, Z.; Fraaije, M. W.; Eijsink, V. G. H.; Vaaje-Kolstad, G. FEBS Lett. 2014, 588 (18), 3435.

(21) Chiu, E.; Hijnen, M.; Bunker, R. D.; Boudes, M.; Rajendran, C.; Aizel, K.; Oliéric, V.; Schulze-Briese, C.; Mitsuhashi, W.; Young, V.; Ward, V. K.; Bergoin, M.; Metcalf, P.; Coulibaly, F. Proc. Natl. Acad. Sci. 2015, 112 (13), 3973.

(22) Shukla, A. K.; Upadhyay, S. K.; Mishra, M.; Saurabh, S.; Singh, R.; Singh, H.; Thakur, N.; Rai, P.; Pandey, P.; Hans, A. L.; Srivastava, S.; Rajapure, V.; Yadav, S. K.; Singh, M. K.; Kumar, J.; Chandrashekar, K.; Verma, P. C.; Singh, A. P.; Nair, K. N.; Bhadauria, S.; Wahajuddin, M.; Singh, S.; Sharma, S.; Omkar; Upadhyay, R. S.; Ranade, S. A.; Tuli, R.; Singh, P. K. Nat. Biotechnol. 2016, 34 (10), 1046.

(23) Walton, P. H.; Davies, G. J. Curr. Opin. Chem. Biol. 2016, $31,195$.

(24) Beeson, W. T.; Vu, V. V.; Span, E. A.; Phillips, C. M.; Marletta, M. A. Annu. Rev. Biochem. 2015, 84 (1), 923.

(25) Meier, K. K.; Jones, S. M.; Kaper, T.; Hansson, H.; Koetsier, M. J.; Karkehabadi, S.; Solomon, E. I.; Sandgren, M.; Kelemen, B. Chem. Rev. 2017, acs. chemrev.7b00421.

(26) Beeson, W. T.; Phillips, C. M.; Cate, J. H. D.; Marletta, M. A. J. Am. Chem. Soc. 2012, 134 (2), 890.

(27) Bissaro, B.; Isaksen, I.; Vaaje-Kolstad, G.; Eijsink, V. G. H.; Røhr, Å. K. Biochemistry 2018, 57 (12), 1893.

(28) Bissaro, B.; Rohr, A. K.; Skaugen, M.; Forsberg, Z.; Horn, S. J.; Vaaje-Kolstad, G.; Eijsink, V. bioRxiv 2016, doi: http://dx.doi.org/10.1101/097022.

(29) Kim, S.; Stahlberg, J.; Sandgren, M.; Paton, R. S.; Beckham, G. T. Proc. Natl. Acad. Sci. 2014, 111 (1), 149.

(30) Hedegård, E. D.; Ryde, U. J. Biol. Inorg. Chem. 2017, 22 (7), 1029.

(31) Bertini, L.; Breglia, R.; Lambrughi, M.; Fantucci, P.; De Gioia, L.; Borsari, M.; Sola, M.; Bortolotti, C. A.; Bruschi, M. Inorg. Chem. 2017, acs. inorgchem.7b02005.

(32) Wang, B.; Johnston, E. M.; Li, P.; Shaik, S.; Davies, G. J.; Walton, P. H.; Rovira, C. ACS Catal. 2018, 8 (2), 1346.

(33) Frandsen, K. E. H.; Simmons, T. J.; Dupree, P.; Poulsen, J. C. N.; Hemsworth, G. R.; Ciano, L.; Johnston, E. M.; Tovborg, M.; Johansen, K. S.; Von Freiesleben, P.; Marmuse, L.; Fort, S.; Cottaz, S.; Driguez, H.; Henrissat, B.; Lenfant, N.; Tuna, F.; Baldansuren, A.; Davies, G. J.; Lo Leggio, L.; Walton, P. H. Nat. Chem. Biol. 2016, 12 (4), 298.

(34) Kuusk, S.; Bissaro, B.; Kuusk, P.; Forsberg, Z.; Eijsink, V. G. H.; Sørlie, M.; Väljamäe, P. J. Biol. Chem. 
2018, 293, 523.

(35) Hofrichter, M.; Ullrich, R. Current Opinion in Chemical Biology. Elsevier Current Trends April 1, 2014 , pp 116-125.

(36) Kracher, D.; Andlar, M.; Furtmüller, P. G.; Ludwig, R. J. Biol. Chem. 2017, jbc. RA117.000109.

(37) Kuusk, S.; Kont, R.; Kuusk, P.; Heering, A.; Sørlie, M.; Bissaro, B.; Eijsink, V. G. H.; Väljamäe, P. J. Biol. Chem. 2019.

(38) Kjaergaard, C. H.; Qayyum, M. F.; Wong, S. D.; Xu, F.; Hemsworth, G. R.; Walton, D. J.; Young, N. A.; Davies, G. J.; Walton, P. H.; Johansen, K. S.; Hodgson, K. O.; Hedman, B.; Solomon, E. I. Proc. Natl. Acad. Sci. 2014, 111 (24), 8797.

(39) Hedegård, E. D.; Ryde, U. J. Biol. Inorg. Chem. 2017, 22 (7), 1029.

(40) Hedegård, E. D.; Ryde, U. Chem. Sci. 2018, 9 (15), 3866.

(41) Baraban, J. H.; Changala, P. B.; Stanton, J. F. J. Mol. Spectrosc. 2018, 343, 92.

(42) Busing, W. R.; Levy, H. A. J. Chem. Phys. 1965, 42 (9), 3054.

(43) Bissaro, B.; Forsberg, Z.; Ni, Y.; Hollmann, F.; Vaaje-Kolstad, G.; Eijsink, V. G. H. Green Chem. 2016, $18,5357$.

(44) Vaaje-Kolstad, G.; Forsberg, Z.; Loose, J. S.; Bissaro, B.; Eijsink, V. G. Curr. Opin. Struct. Biol. 2017, $44,67$.

(45) Loose, J. S. M.; Arntzen, M. Ø.; Bissaro, B.; Ludwig, R.; Eijsink, V. G. H.; Vaaje-Kolstad, G. Biochemistry 2018, 57, 4114.

(46) Hangasky, J. A.; Iavarone, A. T.; Marletta, M. A. Proc. Natl. Acad. Sci. 2018, 115 (19), 4915.

(47) Sabbadin, F.; Hemsworth, G. R.; Ciano, L.; Henrissat, B.; Dupree, P.; Tryfona, T.; Marques, R. D. S.; Sweeney, S. T.; Besser, K.; Elias, L.; Pesante, G.; Li, Y.; Dowle, A. A.; Bates, R.; Gomez, L. D.; Simister, R.; Davies, G. J.; Walton, P. H.; Bruce, N. C.; McQueen-Mason, S. J. Nat. Commun. 2018, 9 (1).

(48) Huber, S. M.; Ertem, M. Z.; Aquilante, F.; Gagliardi, L.; Tolman, W. B.; Cramer, C. J. Chem. - A Eur. J. 2009, 15 (19), 4886.

(49) Hangasky, J. A.; Marletta, M. A. Biochemistry 2018, acs. biochem.8b00129.

(50) Kracher, D.; Andlar, M.; Furtmüller, P. G.; Ludwig, R. J. Biol. Chem. 2018, 293 (5), 1676.

(51) O'Dell, W. B.; Agarwal, P. K.; Meilleur, F. Angew. Chemie 2017, 129 (3), 785.

(52) Brenner, M. C.; Klinman, J. P. Biochemistry 1989, 28 (11), 4664.

(53) Mukherjee, A.; Smirnov, V. V.; Lanci, M. P.; Brown, D. E.; Shepard, E. M.; Dooley, D. M.; Roth, J. P. J. Am. Chem. Soc. 2009, 130 (29), 9459.

(54) Whittaker, M. M.; Ballou, D. P.; Whittaker, J. W. Biochemistry 1998, 37 (23), 8426.

(55) Cole, J. L.; Solomon, E. I.; Ballou, D. P. J. Am. Chem. Soc. 1991, 113 (22), 8544.

(56) Andréasson, L.; Reinhammar, B. Biochim. Biophys. Acta 1976, 445, 579.

(57) Müller, G.; Chylenski, P.; Bissaro, B.; Eijsink, V. G. H.; Horn, S. J. Biotechnol. Biofuels 2018, 11 (209), 1. 